\title{
Competitive Location and Capacity Decisions for Firms Serving Time-sensitive Customers*
}

\author{
Anthony M. Kwasnica ${ }^{\dagger}$ and Euthemia Stavrulaki ${ }^{\ddagger}$
}

June 17, 2008

\begin{abstract}
In this paper we explore how two competing firms locate and set capacities to serve timesensitive customers. Because customers are time-sensitive, they may decline to place an order from either competitor if their expected waiting time is large. We develop a two-stage game where firms set capacities and then locations, and show that three types of subgame perfect equilibria are possible: local monopoly (in which each customer is served by a single firm, but some customers may be left unserved), constrained local monopoly (in which firms serve the entire interval of customers but do not compete with each other), and constrained competition (in which firms also serve the entire interval of customers, but now compete for some customers). We perform a comparative statics analysis to illustrate differences in the equilibrium behavior of a duopolist and a coordinated monopolist.
\end{abstract}

\section{Introduction}

Convenience considerations frequently trump price considerations. For example, customers may decide to purchase from a particular seller primarily because the seller offers fast service and is closely located, or offers a product that closely matches their needs. Thus, firms' capacity and location choices can be important strategic levers. Capacity determines both the speed of order processing and the cost at which this speed can be achieved, and location determines proximity to customers either in tastes or geography. However, faster service, achieved by larger capacity, may not necessarily imply a sufficient increase in the customer base to offset its increased cost if a competitor also increases capacity or locates closer to the firm. In the presence of competition and time-sensitive customers, understanding such interactions between capacity and location decisions is a complex challenge for managers. We address these issues by analyzing a competitive location

\footnotetext{
*We thank the Associate Editor, two anonymous referees, Mike Pangburn, and Shankar Sunderasan for their valuable comments. The order of the authors is alphabetical.

${ }^{\dagger}$ Pennsylvania State University, 332 Business Building, University Park, PA 16802. Email: kwasnica@psu.edu

${ }^{\ddagger}$ Bentley College, Management Department, Waltham, MA 02452. Email: EStavrulaki@bentley.edu
} 
problem with capacity pre-commitment. We provide insights on the equilibrium choices of capacity and location when facilities experience congestion delays for processing customer orders.

Our model considers the traditionally monopolistic issues of capacity and scale economies in a competitive location environment. More precisely, we consider two firms offering a single product at a fixed price to time-sensitive customers who are located uniformly on a line segment and are processed on a first-come, first-served basis. As we discuss later, keeping price exogenous allows us to investigate if capacity is an alternative source of differentiation for a firm.

In order to examine the impact of the capacity decision on eventual location choice, we consider firms which first simultaneously set capacities, and then locations. Both order processing times and customer arrival times are stochastic implying congestion delays for the customers. Customers' overall disutility is due to not only congestion delays, but also their location relative to the firms. Therefore, customers take both of these inconveniences into account when deciding whether to order from firm 1 or 2 , or not at all. The firms, similarly, must consider these inconveniences when choosing their capacities and locations.

Hotelling (1929) was the first to consider two firms competing on a line segment. In Hotelling's model, the line segment reflected a "linear city" implying distance related access costs between a customer's location and the firm. This modeling construct can also be used to represent the perceptual space of differing product qualities (Hotelling 1929, Lerner and Singer 1937). Lancaster (1990) reviews much of the product positioning literature and refers to Hotelling's model as a "horizontal product differentiation" model. Similarly, in our model, the location dimension can be viewed as representing either a particular product characteristic choice or a geographic location. In the former case, a consumer's disutility from distance can be thought of as the distance between the product characteristic point chosen by the firm and the ideal point preferred by the consumer. In the later case, a consumer's disutility from physical distance is due to increased travel times or shipping delays.

By examining a model where capacity is chosen first followed by location, we are naturally focusing on applications where the location choice might be more flexible than the capacity choice, and, in turn, our model is less informative of situations where capacities are easily scaled up or down after location choices have been made. Application examples in the product positioning case include the telecommunications industry and internet content providers, who first commit capacity 
and then determine the attributes of the product provided (such as web content). Application examples in the geographic location case include make-to-order manufacturers with high capital investments in capacity; such firms may first determine whether to purchase an expensive piece of equipment for processing customer orders and then choose an appropriate location for it.

Regardless of the application context, by incorporating capacity choice into traditional competitive location models, we contribute to the related literature in a number of ways. ${ }^{1}$ First, we characterize the set of pure strategy equilibria for the two-stage game previously described. We show that equilibrium capacity choices can be affected by the prospect of spatial competition, and thus can be quite different from capacity choices in a monopolistic setting. Second, we demonstrate that differentiation can be achieved by mechanisms other than price. Though the spatial competition literature (e.g., D'Aspermont et al. 1979) has established price as a source of differentiation, capacity has not yet been studied as a differentiation source within our context. With our work we demonstrate that capacity (instead of price) can be an alternative source of differentiation for firms making both capacity and location decisions. Specifically, we show that, unless capacity costs are so low that each firm wants to serve the entire customer area, firms will choose their capacities and locations to differentiate themselves and move as far apart as is practical. Most importantly, firms will not engage in capacity wars where the forces of competition result in significant overinvestment in capacity. In fact, when capacity costs are low, competing firms will always invest in strictly lower levels of capacity than they would if they were to ignore competition and each act as a single monopolist. At the same time, the required capacity investment, when capacity costs are low, is higher than that of two coordinated firms, with the extra amount of capacity being used as a competitive threat (we refer to this case as constrained competition, in which firms directly compete with each other for some customers). As capacity costs increase, firms reduce their capacity investment and may even decide not to compete directly for the same customers at all (each acting as constrained local monopolists). For sufficiently high capacity costs, some customers may not be served by either firm (the local monopoly case).

While we focus on the three competitive cases mentioned above, we also consider the case when capacity costs are so low that each firm serves the entire customer interval, and provide conditions under which co-location is a symmetric equilibrium outcome. In a similar vein DePalma

\footnotetext{
${ }^{1}$ In section 2 we discuss in more detail how our model relates to specific papers.
} 
et al. (1985) considered demand uncertainty as an alternative means to restore co-location as an equilibrium outcome when price and location are the decision variables.

Finally, we examine the impact on the equilibrium solution of competing firms when problem parameters change and demonstrate that it is quite different from the corresponding impact on the collusive solution. For example, we show that as customers' sensitivity to location costs increase, duopolists' profits will increase for a set (or range) of capacity costs, whereas a monopolist's profits always decrease. Moreover, we show that constrained competitors will maintain the same capacity (and profit) regardless of consumers' time sensitivity or willingness to pay. In contrast, as consumers' willingness to pay increases, two coordinated monopolists will always invest in more capacity and make higher profit. We also illustrate via numerical examples that both profits and consumer surplus differences can be significantly different for the duopolist and monopolist.

The remainder of this paper is organized as follows. In Section 2, we provide a brief literature review, and discuss in detail how our model differs from prior work. Section 3 presents our modeling assumptions and the monopolist's problem. Section 4 analyzes the duopolistic problem. In Section 5, we examine a few numerical examples in order to better understand the impacts of changes in the problem parameters. We discuss other equilibria and our model's relation to other potential models in Section 6, and Section 7 concludes. The proofs are contained in the appendix.

\section{Related Work}

Locating facilities around a customer base has received considerable attention in both the Economics and Operations Management literature. The Economics literature typically explores equilibrium location strategies in a competitive environment. The Operations Management literature typically considers location strategies that minimize travel times and/or transportation costs in a monopolistic environment. Our model blends elements from both research streams by explicitly considering non-homogeneous (in location), time-sensitive customers, and allowing the duopolists to make sequential capacity and location decisions.

Papers that have considered a monopolist's pricing and capacity decisions in the presence of congestion include Mendelson (1985), Mendelson and Whang (1990), Dewan and Mendelson (1990),

Stidham (1992), Rump and Stidham (1998), Ha (1998), Van Mieghem (2000), and Dobson and 
Stavrulaki (2006). With the exception of Dobson and Stavrulaki (2006), none of these papers incorporate customers' locations into their models, but they do consider customers' delay costs. Dobson and Stavrulaki analyze a monopolist's simultaneous location, pricing and capacity decisions when customers are located on a line, are time-sensitive, and incur two types of waiting costs (distance and congestion related). They model congestion related delays via an $\mathrm{M} / \mathrm{M} / 1$ queueing system, and characterize the optimal location and capacity decision for a monopolist serving customers with one or more facilities. We adopt a similar model to Dobson and Stavrulaki (2006); we retain the features of time sensitive consumers and capacity setting decisions but suppress the price decision and add competition.

Another stream of research has considered congestion effects in the presence of competition. One group of papers hold price fixed while varying capacity (Kalai, Kamien and Rubinovitch 1992, Gilbert and Weng 1998), a second group of papers hold capacity fixed and vary price (Li and Lee 1994, Lederer and Li 1997, So 2002), while a third group of papers examines simultaneous, or sequential pricing and capacity decisions (Reitman 1991, Loch 1992, Cachon and Harker 2001, Chayet and Hopp 2002). Chayet and Hopp (2002) provide a comprehensive review of this literature. Among these papers, Kalai et. al. (1992), and Gilbert and Weng (1998) are most similar to our modeling framework, as we also consider competition among firms that are price takers: Kalai et. al. (1992) examined the equilibrium behavior of two competing queues, while Gilbert and Weng (1998) considered a two-server queueing system with an external constraint on the customers' waiting and service times imposed by a coordinating agency. Even though these two papers consider customers' waiting times, they do not explicitly account for customers' waiting costs or locations. Our work enriches this literature by simultaneously incorporating customers' waiting costs and distances in the decision process of two competing firms.

Competitive location models most closely relate with our work. Unlike the competitive congestion models we described above, competitive location models are mainly concerned with pricing and location decisions but ignore congestion effects in the facilities. The topological structure used in competitive location models is either a linear space, a general space, or a network. For a review on general competitive location models see Eiselt, Laporte and Thisse 1993. We adopt the topology of a linear space as in Hotelling's (1929) seminal work, which considered the location of two competing firms on a line. When prices are exogenous, Hotelling derived the principle of minimum 
differentiation, which has inspired a stream of research in subsequent years (D'Aspermont et al. 1979, Economides 1984, DePalma et al. 1985, Eiselt 1998). Much of this work has focused on demonstrating that Hotelling's result is not generic; when the price taking assumption is removed, the principle of minimum differentiation does not hold since firms attempt to reduce price competition through different location choices. Building on Hotelling's framework, we examine the location and capacity decisions of duopolists on a line when congestion effects are present and customers are time-sensitive. Since it is well known that price competition will cause differentiation, we fix prices in order to study how capacity decisions and congestion effects will specifically alter firm behavior. Our work illustrates that capacity can be an alternative source of differentiation for a competing firm. Another feature of Hotelling's model is that demand is inelastic; customers will purchase from the lowest-cost firm regardless of the costs. Under the inelastic demand model, firms have a unilateral incentive to move towards each other because this allows them to 'steal' some of the other firm's customers without sacrificing their own consumers resulting in minimum differentiation. In any model where it is assumed that demand is sufficiently elastic such that customers who face high costs will decide not to purchase, location differentiation will be an equilibrium outcome. By allowing for non-purchasing customers, the individual incentive for a firm to move toward the other firm is offset by the lost customers at the extreme end. Our model allows for elastic demand but does not assume that the parameters will be such that some customers will not want to purchase; firms can select capacity levels such that every customer would want to purchase from them. A contribution of our model, is to show that limited customer purchases and thus location differentiation arises endogeneously out of non-cooperative capacity pre-commitment.

\section{Modeling location and capacity decisions}

We consider two homogeneous firms $(1,2)$ that offer a product at potentially different locations and process customer orders with a limited capacity. Adopting Hotelling's (1929) modeling framework, we can think of two firms competing within a linear city, or choosing their product positioning strategy with respect to a single product dimension. As a simple demonstration, let us consider two internet search engines competitively setting their server capacities and then determining features of their user interface. (In a physical location context, analogous arguments would apply if we 
instead considered two ice cream vendors competitively locating their stands on a beach and selling ice cream at a fixed price.) Since consumers have different user-interface preferences, we can represent the interface characteristics as a point on the unit interval. Assuming consumers will always pick one search engine, they will always utilize the search engine that is closest to their preferred interface. Under this assumption, the only Nash equilibrium is for both search engines to co-locate or select an identical interface that lies at the median of preferences of the consumer population. ${ }^{2}$ Our model adds two key realities to Hotelling's model. First, if the customers find that the search engine is slow, they might be dissuaded from using that engine. Second, the user interface might be so cumbersome for the particular consumer, or the expected congestion be so great, that some potential customers decide to not use search engines at all. When these features are added, the firm must now not only consider their location in terms of user interface, as in the Hotelling model, but they must also decide on a server capacity since a larger server might produce faster searches and thus attract more customers.

We assume price to be exogenous in our model for the following reasons. First, there are many settings where treating price as fixed is natural. For example, for many businesses price is determined by the broader market whereas location and capacity are relevant local choices. In other settings, product prices may be unknown or difficult to compare, due to search or switching costs, at the time of the supplier decision. For example, customers deciding on a grocery store may not have a good way to judge the actual price being charged for a particular good. For such companies convenience becomes the primary source of differentiation. Second, our goal is to better understand the impact of capacity on location decisions independent of the price decision. It is well known that including price as a decision variable will result in product differentiation. The effect of capacity on location decisions is less understood. In a model with both capacity and price variable, if the end result was differentiation, we would be unable to conclude that capacity was a driver for this differentiation. Finally, this assumption enables us to derive analytically tractable results. It is well known that location models with price competition often lack pure strategy equilibria or closed-form solutions (D'Aspermont et al. 1989, Lerner and Singer 1937). If price was added as a final stage of the two-stage game we present in Section 4, the process of determining a subgame

\footnotetext{
${ }^{2}$ In the case of a uniformly distributed population, this would be the middle of the unit interval. Interestingly, this result is also found in the Political Science literature as the median voter theorem (Downs 1957).
} 
perfect equilibrium would require that we find the Nash equilibrium to all proper subgames at the final stage, some of which may not exist, or may not admit closed-form solutions.

We denote the fixed price by $p$, and, without loss of generality, we assume the interval of customers to be $[0,1]$. Let $\left(x_{1}, x_{2}\right)$ denote the points where firms 1 and 2 are located on the line segment. As mentioned earlier, these locations can either be physical locations of facilities or locations of product characteristics. For consistency, we henceforth refer to location in the physical sense. Each firm incurs a marginal cost of capacity $c$, where $p>c>0$, to buy capacity to handle orders at a rate $\mu$. The potentially different capacity choices of firms 1 and 2 are denoted by $\mu_{1}$ and $\mu_{2}$, respectively. Processing orders may involve a customization operation as well as steps for preparing an order for shipment (e.g., credit checking, packaging, and so on). As is common in this literature (e.g., Mendelson 1985, Mendelson and Whang 1990, Dobson and Stavrulaki 2006), we model all such order fulfillment steps for firm $i$ with an $M / M / 1$ queueing system, in which orders arrive with a mean rate $\lambda_{i}$, are processed at a mean rate $\mu_{i}$, and experience an average delay of $W\left(\mu_{i}, \lambda_{i}\right)=\frac{1}{\mu_{i}-\lambda_{i}}$.

We assume that customers located at a point $x$ away from the firm place orders according to a Poisson distribution with a mean rate of $\ell$ orders per unit distance. We also assume that each ordering customer generates a single order per unit time, on average. Therefore, if we let $I_{i}$ denote the set of locations of all customers who decide to purchase from firm $i$, then the arrival process at firm $i$ follows a Poisson distribution with a mean rate of $\lambda_{i}=\int_{x \in I_{i}}(\ell) d x$. Because the firms are price takers, they can manipulate revenue only through location and capacity choices. Thus, the profit of each firm is given by $\pi_{i}\left(\lambda_{i}, \mu_{i}\right)=p \lambda_{i}-c \mu_{i}$.

Customers are homogeneous in that they have the same reservation price $\widehat{p}$ for the product, and the same sensitivity to non-price (convenience) attributes $\alpha$, where $\alpha$ is the unit cost of increased inconvenience. The non-price attributes of a product has two components: the expected delay for order processing, which will depend on how busy the firm is, and the delay for shipping, which will depend on the distance between the customer and the firm. Let $g\left(s_{i}\right)$ be the shipping delay function for a customer at distance $s_{i}$ away from the facility of firm $i$, where $s_{i}=\left|x-x_{i}\right|$, and $x, x_{i}$ are the locations of the customer and firm, respectively. We assume that $g\left(s_{i}\right)=G_{o}+G s_{i}$, where $G_{o} \geq 0$ and $G>0$. In a product differentiation setting, $g\left(s_{i}\right)$ represents how far the firm's offered product is from the customer's ideal product, so it represents customers' perceived disutility from 
obtaining a less than perfect match with their preferences. We also assume that the customer will not know the actual processing delay for an individual order in advance so she decides to purchase based on her expected processing delay, $W\left(\mu_{i}, \lambda_{i}\right){ }^{3}$ Therefore, the expected utility of a customer located at point $x$ who decides to purchase from firm $i$ located at point $x_{i}$ is given by:

$$
U_{x}\left(i \mid x_{i}, \mu_{i}, \lambda_{i}\right)=\widehat{p}-p-\alpha\left(W\left(\mu_{i}, \lambda_{i}\right)+g\left(s_{i}\right)\right)
$$

A customer will choose to buy from a facility if her consumer surplus is non-negative, or a customer at distance $s_{i}=\left|x-x_{i}\right|$ from the facility will not place an order if $U_{x}\left(i \mid x_{i}, \mu_{i}, \lambda_{i}\right)<0$.

\subsection{The Monopolist Case}

In the next sections we will show how a symmetric equilibrium for a duopoly relates to the profit maximizing monopolistic solution. In preparation, in this section we present and characterize how a single, price-taking firm should set capacity to maximize profits. So ignoring competition for the time being, and maintaining the firm subscript $i$ (despite the fact that for the remainder of this subsection there is only one firm), let $I_{i}$ denote the set of locations of all customers who decide to purchase from firm $i$. We assume that the monopolist locates such that $I_{i}$ is completely within the $[0,1]$ interval. This assumption is satisfied as long as the firm does not want to serve the whole interval and locates far away from the boundary points (sufficient conditions on the set of parameters are provided at the end of this section).

We can now characterize in more detail the arrival rate $\lambda_{i}$ for the monopolist. Given our assumptions, we can show that the set of customer locations $I_{i}$ is an interval centered around the facility, with the furthest away customers receiving zero surplus. Let $S_{i}$ denote the distance of the furthest away customer (to the right or left of the facility), not to be confused with the lower-case $s_{i}$ which denotes a generic distance away from the facility. We can express the interval of served customers for firm $i$ as $I_{i}=\left[x_{i}-S_{i}, x_{i}+S_{i}\right]$, and so the mean arrival rate of the order processing system of firm $i$ is $\lambda_{i}=2 \ell S_{i}$.

Since the per unit distance arrival rate $\ell$ is constant, as long as the firm locates such that $I_{i}$ is completely within the $[0,1]$ interval, the monopolist will select the same capacity and be indifferent

\footnotetext{
${ }^{3}$ There are many industries where a customer may query the firm about expected processing delays before she makes a purchase decision. We do not permit such a choice here.
} 
among the set of locations it serves. Therefore, the monopolist's problem is to choose capacity so as to maximize expected profits:

$$
\begin{aligned}
& \max _{\mu_{i}>2 \ell S_{i}>0} \pi_{i}^{M}\left(S_{i}, \mu_{i}\right)=\left(p\left(2 \ell S_{i}\right)-c \mu_{i}\right) \\
& \text { subject to: } \\
& \widehat{p}-\alpha W\left(\mu_{i}, 2 \ell S_{i}\right)-\alpha g\left(S_{i}\right) \geq p .
\end{aligned}
$$

We employ the superscript $M$ to denote the monopolist's profit function and optimal decision variables. We can now more formally show, via the complementary slackness of the Karush-Kuhn Tucker conditions, that the multiplier of the surplus constraint is strictly positive, as long as $p>c>0$, thus ensuring that the surplus constraint is binding.

Solving the (binding) surplus constraint with respect to the capacity variable implies that the optimal capacity is a function of the distance of the furthest away customer $S_{i}$ from the facility. Denote this function as $\widetilde{\mu}_{i}^{M}\left(S_{i}\right)=2 \ell S_{i}+\frac{\alpha}{K-\alpha G S_{i}}$, where $K \equiv \widehat{p}-\alpha G_{o}-p$, represents the maximum amount of surplus of a customer located at the same point as the facility and experiencing no waiting. ${ }^{4}$ Expressing the optimal capacity in this way reveals that $\widetilde{\mu}_{i}^{M}\left(S_{i}\right)$ is convex increasing in $S_{i}$ implying dis-economies of scale for the facility. As a monopolist expands its market to attract more distant consumers, it must decrease its congestion delays to offset the increased travel costs for these more distant customers. Therefore, additional purchasing consumers, located further away, require larger investments in capacity.

Since $\widetilde{\mu}_{i}^{M}\left(S_{i}\right)$ is a strictly convex function of $S_{i}$, the profit function $\pi_{i}^{M}\left(S_{i}, \widetilde{\mu}_{i}^{M}\left(S_{i}\right)\right)$ is strictly concave in $S_{i}$, and the optimal solution is derived via the first order condition. Let $\mu^{M}$ be the optimal solution to the monopolist's maximization problem and $2 S^{M}$ be the corresponding interval served under this capacity. The monopolist maximization problem (2) has a (unique) globally optimal solution, such that:

$$
\mu^{M}=\frac{2 \ell K}{\alpha G}+(p-2 c) \sqrt{(2 \ell) / G c(p-c)} \text { and } S^{M}=\frac{K}{\alpha G}-\sqrt{c / 2 \ell G(p-c)} .
$$

By expressing the optimal monopolistic customer region $2 S^{M}$ analytically and enforcing the inequality $2 S^{M}<1$, we can find conditions on the parameters that satisfy our assumption that the monopolist's interval of served customers is within the $[0,1]$ interval. The firm does not want to

\footnotetext{
${ }^{4}$ We use the 'tilde' symbol to denote a function whenever confusion is possible.
} 
serve the entire interval as long as:

$$
c>p\left(1-2 \alpha^{2} G /\left(2 \alpha^{2} G+\ell(2 K-\alpha G)^{2}\right)\right) .
$$

Once the monopolist is serving less than the whole interval, to maximize profits it will select a location $x_{i}$ larger (smaller) than the distance implied by the interval of customers to the left (right) of the facility (i.e., $S^{M}<x_{i}<1-S^{M}$ ).

Our assumption that the monopolist does not want to serve the entire interval of customers makes capacity an economically important decision, and so we maintain it for the remainder of this paper; we discuss in Section 6.2 the consequences of relaxing this assumption. It is worthwhile, however, to point out that even though condition (4) restricts the monopolist from wanting to serve more than the unit interval, it does not necessarily imply the same restriction for a duopolist (see Section 5.2.1 for a numerical example). One of our contributions is that we prove that the duopolist would often choose not to serve the entire interval.

\section{Competitive capacity and location in a duopoly}

Employing the same framework we introduced in the previous section, we model the decision process of two competing firms as a two-stage game, where the firms simultaneously select capacities $\left(\mu_{1}, \mu_{2}\right)$, and then locations $\left(x_{1}, x_{2}\right)$. As we discussed in the introduction, this stage game reflects environments (in both the product positioning and the facility location contexts) where large ex ante capacity investments are required, but final location is more flexible. Making capacity the first-stage decision agrees with our intention to investigate the impact of capacity choices on a duopolist's location. This order also allows us to characterize the equilibrium outcomes, whereas placing capacity after location would not be analytically tractable. In Section 6.3, we discuss how our results can be applied to other incarnations of this game.

Once firms have made their choices, consumers select the firm that offers them the highest expected utility, or they do not purchase if neither firm offers them a positive expected utility. Due to the uniform nature of the consumer distribution, as long as the monopolist is located such that $2 S^{M}$ is entirely within the $[0,1]$ interval, he is indifferent among locations. In the competitive 
setting, however, a firm's location can be an important strategic variable.

Using backward induction to identify the subgame perfect equilibrium, we begin by analyzing the location (second) stage. Each customer has a choice of three alternatives: purchasing from firm 1, purchasing from firm 2, or not purchasing at all. Recall from Section 3 that $U_{x}\left(i \mid x_{i}, \mu_{i}, \lambda_{i}\right)$ is the expected utility (or surplus) of a consumer located at point $x$ who purchases from firm $i$ located at point $x_{i}$. The arrival rate of consumers served by a particular firm $\lambda_{i}$ is now a function of the capacity and location choices of the two firms $\left(x_{1}, \mu_{1}\right)$ and $\left(x_{2}, \mu_{2}\right)$. Therefore, we rewrite the consumer's expected utility to be a function of both firms' capacity and location choices as $U_{x}\left(i \mid\left(x_{1}, \mu_{1}\right)\left(x_{2}, \mu_{2}\right)\right)$ given that the two firms have made (location, capacity) choices of $\left(x_{1}, \mu_{1}\right)$ and $\left(x_{2}, \mu_{2}\right)$, for $i=1,2$, where $x, x_{1}$ and $x_{2}$ all are points in the $[0,1]$ interval. Let $\mu_{i}$ be the capacity choice of the firm $i$ from the first (capacity setting) stage, and $\widetilde{S}_{i}^{M}\left(\mu_{i}\right)$ be the function of capacity $\mu_{i}$ that defines the furthest away, non-negative surplus customer served if firm $i$ were a monopolist. ${ }^{5}$ Without loss of generality, we assume that firm 1 always locates to the left and firm 2 always locates to the right, or $x_{1} \leq x_{2}$.

Proposition 1 For any capacity choices $\left(\mu_{1}, \mu_{2}\right)$, such that both firms would serve less than the whole interval as monopolists, $\left(\widetilde{S}_{1}^{M}\left(\mu_{1}\right)<\frac{1}{2}\right.$ and $\left.\widetilde{S}_{2}^{M}\left(\mu_{2}\right)<\frac{1}{2}\right)$, there exists a Nash equilibrium in the second (location) stage where firms select locations $x_{1}^{*}$ and $x_{2}^{*}$ such that the extreme consumers receive zero expected surplus $\left(U_{0}\left(1 \mid\left(x_{1}^{*}, \mu_{1}\right)\left(x_{2}^{*}, \mu_{2}\right)\right)=0\right.$, and $\left.U_{1}\left(2 \mid\left(x_{1}^{*}, \mu_{1}\right)\left(x_{2}^{*}, \mu_{2}\right)\right)=0\right)$.

The preceding proposition shows that, when both firms are serving less than the whole interval, an equilibrium in the second stage exists where the two firms move away from each other. However, they will only move far enough apart such that the extreme customer - the customer at point 0 for firm 1 and the customer at point 1 for firm 2 - is exactly indifferent between purchasing and abstaining. Any movement further apart would lead to lost customers on the other side of the firm (towards the center). Any movement closer would result in lost customers on the extreme side for that firm. In fact, subject to the constraint that $x_{1} \leq x_{2}$, it is a weakly dominant strategy for each firm to select the locations described in the proposition above. ${ }^{6}$

\footnotetext{
${ }^{5}$ The function $\widetilde{S}_{i}^{M}\left(\mu_{i}\right)$ is simply the positive root derived when inverting $\widetilde{\mu}_{i}^{M}\left(S_{i}\right)$ introduced in the previous section.

${ }^{6}$ Technically, this equilibrium is not a dominant strategy equilibrium because one firm could select a (sub)optimal location such that the other firm would want to jump to the other side of that firm. However, once that firm jumped to the other side of that firm, the firm would want to locate itself such that its new extreme consumer received zero expected utility.
} 
We can now consider the first stage of the game. If the firms select capacities $\mu_{i}$ such that $S_{i} \leq \frac{1}{4}$, their payoffs are characterized by the monopolist's problem. We thus focus on the case where firms directly compete with each other for some customers (when $S_{i}>\frac{1}{4}$ ). We call this the constrained competition case. In this case, even though we will see that each firm will serve exactly half the interval of customers $\left(\lambda_{i}^{*}=\frac{1}{2} \ell\right)$ in equilibrium, some customers in the middle of the interval have a choice of being served by either firm, and decide between them based on their surplus amount they expect to receive from each one. For now, we allow firms to choose different capacities, and we focus on the area of competition of a firm with the other (i.e., the area in which consumers receive positive surplus from both firms). Observe, from Figure 1 that the interval of competition to the left and to the right of the overlap point between the two firms (denoted by $z$ ) is the same. This observation is independent of the particular capacity choices of the other firm since the rate of change of customer surplus as one moves closer to each firm is only a function of the shipping delay function (see Figure 1). Therefore, $2 z$ is the interval of overlap between the two firms, and firm $i$ serves an area equal to $S_{i}+\left(S_{i}-z\right)$, for $i=1,2$. We also know from Proposition 1 that firms will always serve customers at the end points of $[0,1]$ so the only equilibrium where the firms compete for customers is one where together they serve the whole interval. Therefore, $S_{1}+\left(S_{1}-z\right)+S_{2}+\left(S_{2}-z\right)=1$, and we can now eliminate the overlap variable $z$ by substituting $z=S_{1}+S_{2}-\frac{1}{2}$. Thus, the mean arrival rate for firm $i$ is equal to $\lambda_{i}=\ell\left(S_{i}+\left(S_{i}-z\right)\right)=\ell\left(S_{i}-S_{j}+\frac{1}{2}\right)$ where $j \neq i$.

Letting the superscript $C$ refer to the constrained competition case, we can formulate the Constrained Competition Model (CCM) for firm 1 given a choice of $\mu_{2}$ as follows:

$$
\max _{\mu_{1}>\ell\left(S_{1}-S_{2}+\frac{1}{2}\right)>0} \pi_{1}^{C}\left(S_{1}, S_{2}, \mu_{1}, \mu_{2}\right)=\left(p \ell\left(S_{1}-S_{2}+\frac{1}{2}\right)-c \mu_{1}\right)
$$

subject to:

$$
\begin{aligned}
\widehat{p}-\frac{\alpha}{\mu_{1}-\ell\left(S_{1}-S_{2}+\frac{1}{2}\right)}-\alpha G_{o}-\alpha G S_{1} & =p, \\
\widehat{p}-\frac{\alpha}{\mu_{2}-\ell\left(S_{2}-S_{1}+\frac{1}{2}\right)}-\alpha G_{o}-\alpha G S_{2} & =p, \\
S_{1}+S_{2}-1 / 2 & >0 .
\end{aligned}
$$

Firm 2's maximization problem given a choice of capacity by firm 1 is expressed similarly. We know that constraints (6) and (7) will be binding, for any feasible capacity choice $\mu_{2}$ by firm 2 
from Proposition 1. While, as these constraints bare witness to, $S_{1}$ and $S_{2}$ are functions of $\mu_{1}$ and $\mu_{2}$, we suppress the functional dependence for notational convenience. The two surplus constraints incorporate the second stage behavior of each firm into the decision making of the first stage, according to Proposition 1. Constraint (6) is the zero utility condition for the consumer located at $x=0$ and constraint (7) is the zero utility condition for the consumer located at $x=1$. The final constraint (8) ensures that we are in the constrained competition case; there is a strictly positive overlap between the firms. A Nash equilibrium in the first stage will consist of $\left(\mu_{1}^{*}, \mu_{2}^{*}\right)$ such that $\mu_{i}^{*}$ is a solution to the CCM given $\mu_{j}^{*}$. For the moment, let us consider each firm's profit maximizing decision separately. We begin by showing that for each choice of $\mu_{2}\left(\mu_{1}\right)$, firm 1(2) has a unique best response.

Proposition 2 When constraint (8) is satisfied (i.e., non-binding), the CCM has a (unique) globally optimal solution.

In contrast to the monopolist case, we cannot derive closed-form expressions for the optimal solution of the CCM. However, we can compare the CCM solution with the monopolist's optimal solution expressed in equation (3). Given a capacity choice $\mu_{2}$ by firm 2 , let $\widetilde{\mu}_{1}^{C}\left(\mu_{2}\right)$, and $\widetilde{S}_{1}^{C}\left(\mu_{2}\right)$ denote the optimal solution to the CCM for firm 1 as functions of $\mu_{2}$. Note also that the function $\widetilde{S}_{1}^{C}\left(\mu_{2}\right)$ defines the furthest away, non-negative surplus customer served by firm 1 , given capacity $\mu_{2}$ for firm 2 .

Proposition 3 The optimal solution of the CCM for firm 1 is such that the firm serves a strictly smaller interval of customers $\left(\widetilde{S}_{1}^{C}\left(\mu_{2}\right)<S^{M}\right)$ and selects a strictly lower capacity $\left(\widetilde{\mu}_{1}^{C}\left(\mu_{2}\right)<\mu^{M}\right)$ than a monopolist, given any choice of capacity by firm 2 such that constraint (8) is satisfied (i.e., non-binding).

An equivalent proposition holds for firm 2. The intuition behind this proposition is simple. When the firms are overlapping, the return on increases in capacity is reduced because increases in capacity just increase the overlap between firms. Therefore, given that the cost of capacity is the same, a firm will want to invest in less capacity if it is competing with another firm than it would as a monopolist. Therefore, when condition (4) holds, ensuring that a monopolist will serve less than the whole interval, we know that, the duopolists will also serve less than the whole interval 
in equilibrium. Importantly, this means that the antecedent of Proposition 1 is satisfied so the proposition can be used to characterize the location choices of the firms in equilibrium.

Once firms start competing, Proposition 3 also suggests that there will be a discontinuous reduction in their benefits from capacity investments, implying that there will exist a range of parameter values such that the firms are between monopolistic behavior (no overlap) and constrained competition behavior (positive overlap). Figure 2 depicts how the marginal revenue of one firm varies as its capacity increases while the capacity choice of the other firm remains fixed. The Figure illustrates the gap in marginal revenue that separates the monopolistic and constrained competition cases. We see from Figure 2 that the type of symmetric equilibrium depends on where the marginal cost of capacity $c$, which in the figure would be depicted as a straight horizontal line, intersects the marginal revenue function. Proposition 4 formalizes these observations and characterizes a symmetric equilibrium of the game.

Proposition 4 There exists cost thresholds $c_{M}$ and $c_{L}$ such that the following constitutes a symmetric subgame perfect equilibrium:

i. If $c \geq c_{M}$, then $\mu_{1}^{*}=\mu_{2}^{*}=\mu^{M}$ and $x_{1}^{*}=S^{M}$ and $x_{2}^{*}=1-S^{M}$.

ii. If $c_{M}>c \geq c_{L}$, then $\mu_{1}^{*}=\mu_{2}^{*}=\frac{l}{2}+\frac{\alpha}{K-\alpha G / 4}$ and $x_{1}^{*}=\frac{1}{4}$ and $x_{2}^{*}=\frac{3}{4}$.

iii. If $c<c_{L}$, then $\mu_{1}^{*}=\mu_{2}^{*}$ such that $\mu_{1}^{*}=\widetilde{\mu}_{1}^{C}\left(\mu_{2}^{*}\right)$ and $\mu_{2}^{*}=\widetilde{\mu}_{2}^{C}\left(\mu_{1}^{*}\right)$, and $x_{1}^{*}=\frac{K}{\alpha G}-\frac{1}{G\left(\mu_{1}^{*}-\ell / 2\right)}$ and $x_{2}^{*}=1-\left(\frac{K}{\alpha G}-\frac{1}{G\left(\mu_{1}^{*}-\ell / 2\right)}\right)$.

The cost thresholds $c_{M}$ and $c_{L}$ are formally defined in the proof provided in the appendix. The three equilibrium types are illustrated in Figure 3. In the first case, the marginal cost of capacity $c$ is sufficiently high (i.e., $c \geq c_{M}$ ) so that the firms would, as monopolists, select a capacity level that causes them to serve less than half the interval of customers. Therefore, firms are able to act like local monopolists.

In the second case, the marginal cost of capacity is low enough such that, if the firms were monopolists, they would individually decide to serve more than half of the customers. In order to capture more customers, the firms must now consider directly competing with each other by offering positive expected utility to some customers who also receive positive expected utility from the other firm. Such direct competition effectively reduces the incremental benefit of investments in 
capacity (Proposition 3). In fact, the reduction is significant enough to induce both firms to select a capacity that serves exactly half the interval of customers. We call this case constrained local monopoly to capture the fact that, while all consumers only see one firm that provides them with positive surplus, both firms are constrained by competitive forces from increasing their capacity.

In the final constrained competition case, the marginal cost of capacity is sufficiently low (i.e., $\left.c<c_{L}\right)$ such that, despite the reduced benefit of capacity investments associated with competition, both firms decide to invest in additional capacity. While the equilibrium capacity choices are not characterized by a closed form solution, the location, given an optimal capacity choice, must be such that the extreme point customers are indifferent between purchase and non-purchase in accordance with Proposition 1. Despite this additional investment in capacity the firms, in equilibrium, still serve only half the interval of customers. This increased capacity only serves to discourage the competitor from expanding any further.

\section{$5 \quad$ Numerical comparisons}

In this section we investigate changes in the equilibrium predictions as the various problem parameters vary. We begin by examining the values that lead to the three different types of symmetric equilibria identified in Proposition 4. Then we examine the constrained competition case in more detail.

In our numerical examples in this section, we employ a base case scenario that sets $\widehat{p}=\$ 25$, $p=\$ 20, \ell=10$ customers per unit distance, $c=\$ 5, G_{o}$ and $G$ at $\$ 0$ and $\$ .50$ per unit distance, respectively, and $\alpha=\$ 15$ per unit time.

\subsection{Equilibrium Regions}

Figure 4 shows the various equilibrium type regions in relation to the marginal cost of capacity $(c)$ as a single parameter is varied around the base case. The feasible equilibrium regions are shaded: local monopoly (darkest), constrained local monopoly (medium), and constrained competition (lightest). The unshaded regions represent parameter values that are not permitted by our assumptions. The assumption that the monopolist would serve less than the whole interval generally restricts the 
feasible region at low costs of capacity. ${ }^{7}$ The constraint $p \geq c$ must also be considered when varying $p$.

As demonstrated in figure 4, all equilibrium types occur for significant portions of the parameter set. Obviously, constrained competition equilibria are associated with lower costs of capacity and local monopoly equilibria are associated with the highest capacity costs.

\subsection{The constrained competition case}

We wish to compare our model of duopoly with monopoly outcomes. For a proper comparison of the duopoly case, we consider a monopolist serving the same customer interval with two facilities (or products). Considering two monopolistic facilities is akin to assuming that the two competing firms merge into a single coordinated firm, and is similar to comparisons in related literature (see for example Lederer and Hurter 1986). In order to differentiate this situation from one facility monopoly discussed previously, we refer to it as coordinated monopoly. Observe that when capacity costs are large enough to imply the local or constrained monopoly cases, as described in Proposition 4 , then the equilibrium capacity and location choices would be identical regardless of whether we consider two competing or two coordinated firms. Therefore, we focus on the constrained competition case for the remainder of this section. When capacity costs are low enough to warrant constrained competition, the optimal solution for two coordinated monopolists would be for each to serve exactly half the consumer interval, with no customer receiving positive surplus from more than one facility; Dobson and Stavrulaki 2006 prove that the optimal way to serve a finite interval of uniformly located consumers with a number of facilities will always be such that the facilities are identical and have non-overlapping service regions. Since the coordinated monopolists do not have to purchase additional capacity to deter competition, we can thus conclude that their capacities will always be lower than the equilibrium capacities of the constrained duopolists. Since competition leads to a higher investment in capacity, we can also conclude that the constrained duopolists would be closer (less differentiated) so that their end customers still receive zero surplus Moreover, the constrained duopolists will be making less profits and offering higher surplus to their customers. What is not clear is if such differences can be significant, and if the coordinated monopolist and

\footnotetext{
${ }^{7}$ We discuss this restriction in Section 6.2 and illustrate the equilibrium behavior with our numerical example in this section.
} 
duopolist would react differently to increases in the problem parameters. We investigate these questions next.

\subsubsection{Profits and consumer surplus comparisons}

We first compare profits and consumer surplus for the duopoly and coordinated monopoly cases Define consumer surplus as the total surplus (realized by all customers) served by two coordinated monopolists or two facilities of a duopolist; graphically, consumer surplus, denoted by $R$, is given by the area under the triangles depicted in Figure 3 (type 1 or 2). For the two coordinated monopolists, the consumer surplus realized equals $(\widehat{p}-p-\alpha W(\mu, \lambda)) 2 S$. The consumer surplus realized by the two facilities of a constrained duopolist is calculated similarly, but also accounts for the triangle of overlap (as depicted in Figure 3 (type 3)).

Since we do not have closed-form equilibrium solutions in the constrained competition case, we perform the analysis numerically; we do have closed-form results for the coordinated monopolists. Table 1 reports the equilibrium values for the base case scenario we introduced in Section 5.1.

Observe that since $z^{*}=.20$, the amount of overlap among the two competing firms is strictly positive. As with any symmetric equilibrium in the constrained competition equilibrium region, the realized interval of served customers by each firm is exactly half the interval (i.e., $S_{1}^{*}+S_{2}^{*}-z^{*}=$ $0.35+0.35-0.2=0.5)$. Observe also that each coordinated monopolist makes higher profits, and provides consumers with lower consumer surplus.

Figure 5 generalizes the results in Table 1 by plotting profit and surplus ratios of two facilities under the duopoly and coordinated monopoly scenarios as capacity costs vary. The three plots in Figures 5(a) and 5(b) correspond to three different values of $\alpha$. Since condition (4) is merely sufficient to ensure that the equilibrium results of Proposition 4 hold, in our numerical examples we relax this condition and find that the constrained competition equilibrium often exists for capacity costs significantly lower than the corresponding lower bound of $c$ implied by condition (4). We found that a constrained competition equilibrium existed when the marginal cost of capacity was approximately $c \approx 2.2$, for $\alpha=15, c \approx 0.6$, for $\alpha=17.5$, and $c=0$, for $\alpha=20$, whereas the corresponding lower bounds from condition (4) were 4.35, 0.97, and 0 respectively.

For our base case scenario, with $\alpha=15$, because the minimum capacity cost ensuring that a monopolist will not serve the whole interval is 4.35 (from condition (4), and the threshold points 
that determine the three equilibrium regions (from Proposition 4) are $c_{L}=6.34$ and $c_{M}=12.69$, we know that when $4.35<c<6.34$ we have the constrained competition case. In this region we see that profit ratios gradually fall to 1 , while consumer surplus ratios gradually increase towards 1 illustrating that as capacity costs increase towards the constrained local monopoly region (when $6.34<c<12.69$ ) the duopolistic and monopolistic scenarios converge. (Similar results hold as the time sensitivity parameter increases to $\alpha=17.5$ and $\alpha=20$.) Observe that, as expected, the larger consumer surplus differences between the duopoly and monopoly cases occur for low values of the capacity cost. Moreover, observe that the shape of each profit ratio is concave until it plateaus at 1 , and that for a given capacity cost, the profit ratio decreases as time sensitivity increases. We can explain the concave shape of the profit ratios in Figure 5(a) by noting that as capacity costs increase, both the duopoly and coordinated monopoly profits decrease (see Table 2 in the next subsection) but monopoly profits decrease linearly while duopoly profits decrease at an increasing rate. We can explain the decrease in the values of the profit ratio as $\alpha$ increases by noting that while duopoly profits remain constant as $c$ increases (see Table 2), monopolist profits decrease. Finally, observe that the profit and surplus differences can be quite significant; for our parameter values, there was a maximum difference ranging between $16 \%$ and $26 \%$ for profits and $50 \%$ to $57 \%$ for surpluses (for the three values of the unit inconvenience cost $\alpha$ we considered).

\subsubsection{Comparative statics}

We now investigate the impact of parameter changes on both firms' profits and consumer surplus. As in the prior section, we also compare our results with the corresponding results for a coordinated monopolist serving the same customer interval with two facilities. We focus on four key problem parameters $(c, \widehat{p}, a$, and $G)$, and explore how the equilibrium solutions change as each parameter increases by a small amount. The changes we consider are always sufficiently small so that the outcome remains in the constrained competition case. We again employ the base case data throughout our analysis; the results are consistent with those produced for various other parameter choices. We summarize our conclusions in Table 2. The entries in each cell indicate the direction of change $(-,+$, or 0$)$ for a particular decision variable given a small increase in the input parameter and holding all other parameters fixed at the base case.

As illustrated in Table 2, when $c$ increases, each duopolist lowers her capacity, and makes less 
profit, while consumer surplus also decreases. As each duopolist lowers her capacity, the effective overlap area $z$ decreases, implying a shift away from her competitor. In contrast, since the two monopolistic facilities can coordinate their choices and all consumer characteristics are unchanged, the facilities need not adjust their capacity as $c$ increases (but $c$ remains high enough to guarantee coverage of the entire customer interval). Therefore, each monopolist continues to serve exactly half the interval with the same capacity, but at a lower profit.

When $\widehat{p}$ increases, we see in Table 2 that each coordinated monopolist can take advantage of the higher value that consumers now place on the product. The monopolists can thus decrease their capacity (and increase profits) while still serving the entire interval and extracting the same surplus from customers. Interestingly, when $\widehat{p}$ increases, the constrained duopolist must maintain the same capacity to remain competitive and so its profits also remain fixed. However, because consumers are now willing to pay more for the product and capacity remains the same, the duopolists must shift towards the center to ensure zero surplus to the edge customers, so the overlap area increases and consumers are better off.

The impact of an increase to the consumers' time sensitivity parameter $\alpha$ is the opposite from the impact of an increase in their reservation price. When $\alpha$ increases, the coordinated monopolists increase their capacity decreasing profits, whereas the duopolists shift away from each other reducing competition and consumer surplus.

Finally, in Table 2 we also see that the impact of an increase in $G$ is identical to that of an increase in $\alpha$ for the coordinated monopolists, but not for the constrained duopolists. In the constrained competition case, increases in $G$ imply that while consumers' surplus and capacity decrease, profits increase. For the base case scenario we consider, as $G$ increases from .5 to .6, the increase in profit is approximately $7 \%$. To explain this counter-intuitive result, observe that an increase in the shipping delay parameter $G$ only impacts the shipping delay portion of a consumer's overall waiting, unlike changes to $\alpha$ which impacts both types of customer waiting (congestion and shipping delays) in the same way. As a result, when $\alpha$ increases, the firm cannot trade-off an increase in the queueing delay with a decrease in the shipping delay, because both types of delays are equally important to the consumer. In contrast, when $G$ increases, the duopolist will decrease shipping delay costs for the furthest away consumers by moving towards them while simultaneously increasing the average congestion-related waiting costs by decreasing capacity. The decrease in 
capacity means that the area of overlap between the competitors will decrease. By shifting away from the center, each duopolist's profits will increase, while reducing the overall consumer surplus.

\section{Model extensions}

In this section, we discuss alternative equilibria and extensions of the model.

\subsection{Asymmetric equilibria}

We have focused on symmetric equilibria, in which the identical firms select the same capacity. ${ }^{8}$ The discontinuity in the marginal revenue curves of the firms as depicted in Figure 2 means that there will also be multiple asymmetric equilibria. Even with asymmetric choices of capacity, it is possible that both firms will operate in the discontinuous portion of their marginal revenue curves. These asymmetric equilibria stem from the fact that if one firm assumes that the other firm will select a large capacity, it might be rational for the firm to select a lower capacity rather than to compete. Consider the base case described in the previous section $\left(\widehat{p}=25, p=20, \ell=10, G_{o}=\right.$ $0, G=.5, \alpha=15)$. If the cost of capacity were $c=10$, then the symmetric equilibrium would dictate that each firm serves exactly half the interval without any overlapping customers and with corresponding capacities $\mu_{1}^{*}=\mu_{2}^{*}=9.8$. On the other hand, if firm 1 selects a capacity of $\mu_{1}=11.45$ serving $60 \%$ of the interval, firm 2's best response is to select capacity $\mu_{2}=8.28$ serving only $40 \%$ of the interval. This asymmetric solution is also an equilibrium because the cost of capacity still falls within the range of discontinuity for both firms so it is also a best response to the other firm's capacity choice. The marginal revenue curves are similar to the one depicted in Figure 2 except that for firm 1(2) the discontinuity has moved to the right(left) since they now encounter overlap when they serve 60(40) percent of the interval. These asymmetric equilibria are similar to the constrained local monopoly case analyzed in the previous section, where both firms do not find it profitable to overlap with the other firm. The following proposition characterizes the feasible asymmetric equilibria given a particular marginal cost of capacity. Firm 1 is assumed to be the larger firm without loss of generality.

\footnotetext{
${ }^{8}$ The equilibrium is also symmetric in terms of the location stage in that both firms locate at equal distances from the endpoints.
} 
Proposition 5 For any distances $S_{1}$ and $S_{2}$ such that the firms serve exactly the whole interval $\left(S_{1}=\frac{1}{2}-S_{2}\right)$ and firm 1 is larger than firm $2\left(S_{1}>S_{2}\right)$, if

$$
\left(\frac{\left(\frac{K}{\alpha G}-S_{1}\right)^{2} 2 \ell}{1+\left(\frac{K}{\alpha G}-S_{1}\right)^{2} 2 \ell}\right) p \geq c \geq\left(\frac{\left(\frac{K}{\alpha G}-S_{2}\right)^{2} 2 \ell(1-T)}{1+\left(\frac{K}{\alpha G}-S_{2}\right)^{2} 2 \ell(1-T)}\right) p
$$

where $T=\frac{1}{2}\left(1-\frac{w}{\sqrt{w^{2}+\frac{4 \ell}{G}}}\right)$ and $w=2 \ell S_{1}+\frac{\alpha}{K-\alpha G S_{1}}-\ell\left(\frac{K}{\alpha G}-S_{2}+\frac{1}{2}\right)$, then $x_{1}^{*}=S_{1}, x_{2}^{*}=1-S_{2}$ and $\mu_{1}^{*}=2 \ell S_{1}+\frac{\alpha}{K-\alpha G S_{1}}, \mu_{2}^{*}=2 \ell S_{2}+\frac{\alpha}{K-\alpha G S_{2}}$ is an asymmetric subgame perfect equilibrium.

Employing Proposition 5 for our base case example, we can conclude that the most asymmetric equilibrium that can be supported when $c=10$ has the larger firm (firm 1 for convenience) service just over $70 \%$ of the customers.

There also exist an infinite number of equilibria when parameters are in the local monopoly type range (case $i$. in Proposition 4). In this case, any location where the two firms do not overlap would also be an equilibrium. All these equilibria are payoff equivalent, so it is without loss of generality that we focus on the particular equilibrium identified by Proposition 1. Finally, since we have multiple pure strategy equilibria in both stages, there will also exist mixed strategy equilibria.

\subsection{Removing assumptions}

The assumption that the monopolist would not want to serve the entire interval, expressed in condition (4), reduces the set of feasible parameters as illustrated in Figure 4. The motivation for this assumption was to create an environment where capacity was a realistic and important choice variable, or the interval represents a large world of consumers. Since situations that violate condition (4) are similar to the original model presented by Hotelling, where all consumers are assumed to purchase from some firm, we consider what might happen if condition (4) is dropped.

Recall that condition (4) is sufficient but not necessary to guarantee the result in Proposition 1. Since we proved that $S^{C}<S^{M}$ (Proposition 3), we know that duopolists will likely serve less than the entire interval when capacity costs are lower than the ones suggested by the condition. Given the sizable gap we observed in the marginal revenue for the local monopoly and the constrained competition cases, it is likely that for many more parameter values than the ones highlighted in Figure 4, firms will be participating in constrained competition, and will not select capacities that provide the whole interval of customers with positive expected surplus. Consider the base case 
example developed in the previous section. As discussed in Section ??, while the cutoff implied by condition (4) is that $c>4.35$, the competing firms will continue in the constrained competition case until $c \approx 2.2$. And when $\alpha$ increases to 20 , the condition is not binding so that all values of $c$ satisfy condition (4).

There are undoubtedly, however, situations where the cost of capacity is sufficiently low such that the two firms might unilaterally decide to serve the whole interval. For example, internet content providers may fit in this category since the cost of increased server capacity is typically considered to be very low. This might mean that a firm will offer consumers on both endpoints a positive surplus. In this situation, Proposition 1 is no longer a valid characterization of equilibrium play in the second stage. But, at least for symmetric equilibria, we can show that there exists a statement similar to Proposition 1 about the location stage of the game.

Proposition 6 For any symmetric capacity choices $\mu_{1}=\mu_{2}$ such that each firm would serve the whole interval $\left(\widetilde{S}_{1}^{C}\left(\mu_{2}\right)=\widetilde{S}_{2}^{C}\left(\mu_{1}\right) \geq \frac{1}{2}\right)$, it is a Nash equilibrium for firms to select $x_{1}^{*}=x_{2}^{*}=\frac{1}{2}$.

For all subgames where firms have made the same capacity choices in the first stage and those capacities entail serving the entire interval, the Nash equilibrium of the second stage will be for the two firms to co-locate. Co-location and equal capacities will result in each firm serving half the customers. Any movement away from the middle point, cannot capture the firm more than half the interval of customers. All customers in the opposite direction of the firm's move will prefer the firm in the middle since that firm is closer and offers the same capacity. This reasoning is identical in nature to the traditional Hotelling result.

While Proposition 6 tells us that any symmetric subgame perfect equilibrium where firms serve the whole interval will involve colocation, it does not prove that such an equilibrium exists. In order for such an equilibrium to exist, the assumed capacity choices of each firm must also constitute a Nash equilibrium. In order to prove this we next investigate each firm's best response to the other firm's capacity choices. When the firms co-locate in the second stage, consumers will only differentiate the firms by the expected waiting time offered. We assume that, if a consumer is indifferent between firms, then she is willing to randomize between firms in any proportion (since she is indifferent between firms any such mixing will yield the same expected utility to the consumer). In this case, the only possible equilibrium for the consumer choices will be an outcome such that 
the expected waiting times are equal; otherwise, all consumers would prefer to purchase from the firm with a lower waiting time, but this outcome would not be stable since the other firm would now offer a lower waiting time. Observe also that if $\mu_{1}=\mu_{2}$, then equating the expected waiting times implies that both firms will serve half of the customers or $\lambda_{1}=\lambda_{2}=.5 \ell$.

We can now partially describe the equilibrium when condition (4) is dropped. When the firms co-locate in the second stage and consumers select firms probabilistically to equate waiting times, it is easy to show that the payoff function with respect to changes in a firm's capacity is linear. This linearity drives the following result.

Proposition 7 When the solution to the CCM is such that both firms would optimally serve the entire interval $\left(\widetilde{S}_{1}^{C}\left(\mu_{2}^{*}\right)=\widetilde{S}_{2}^{C}\left(\mu_{1}^{*}\right) \geq \frac{1}{2}\right)$, and

i. $p<2 c$, then the pure strategy symmetric subgame perfect equilibrium will be such that the extreme customers are indifferent between purchase and not and the firms will co-locate, or $\mu_{1}^{*}=\mu_{2}^{*}=\frac{1}{\frac{K}{\alpha}-.5 G}+.5 \ell$ and $x_{1}^{*}=x_{2}^{*}=\frac{1}{2}$.

ii. $p>2 c$, then there is no symmetric pure strategy subgame perfect equilibrium.

In the first case of Proposition 7, the cost of capacity is sufficiently high such that, if the firms want to serve the whole interval, they will have no incentive to continue to invest in capacity beyond the minimum amount required to serve all customers. In the second case, despite the prospect of future co-location, the cost of capacity is so low such that each firm has a unilateral incentive to purchase additional capacity in order to entice more customers to purchase from them. The linearity in the payoff terms implies that there will not be an equilibrium in this case. It is important to note that the second case of Proposition 7 may be common. In order to be in a colocation situation, the cost of capacity must already be so low that the three types of equilibria described in Proposition 4 are not possible. In the base case example we have used throughout, the price $p=20$ and the lowest cost of capacity that is captured by the constrained competition case is $c=2.2$ when $\alpha=15$, so there would clearly be no symmetric equilibrium when the capacity cost reduces further (since $p=20>2 c=2(2.2)$ ). 


\subsection{Other game forms}

We have focused so far on a particular extensive form of our model; firms select capacity and then location. While this is a reasonable description of the choice procedure for a number of settings, there are other situations where other specifications are more reasonable. One might imagine that location is chosen first and then capacity, or that firms select both simultaneously. In both cases, since the games have the same normal form representation, the equilibria we identified would also be Nash (but not necessarily subgame perfect) equilibria of those games (Fudenberg and Tirole 1993).

Let us briefly consider the simultaneous move (normal form) version of the game where both firms select capacity and location simultaneously. Given that it is a weakly dominant strategy for each firm to select a location such that the extreme consumers receive zero surplus, an analog to Proposition 1 can easily be stated.

Proposition 8 If neither firm would serve the whole interval as a monopolist $\left(\widetilde{S}_{1}^{M}\left(\mu_{1}^{*}\right)<\frac{1}{2}\right.$ and $\left.\widetilde{S}_{2}^{M}\left(\mu_{2}^{*}\right)<\frac{1}{2}\right)$, then for the simultaneous move game there is no Nash equilibrium in which extreme customers receive positive surplus.

The intuition behind the proof is the same as Proposition 1. If the firms are providing positive surplus to the extreme customer closest to them, they will have a unilateral incentive that is also independent of the capacity choices to move towards the center of the interval. By moving towards the center, the firms will not decrease (and probably increase) the customers that purchase from them without changing their costs. Therefore, we can also conclude that the equilibrium identified in Proposition 4 must also be the unique symmetric Nash equilibrium for the simultaneous move game that involves firms serving less than the whole interval. ${ }^{9}$ It is, however, possible that there exist Nash equilibria of the simultaneous move game (and hence subgame perfect equilibria of the game with a reversed order) that involves consumers at the endpoints receiving positive surplus even when condition (4) is assumed to hold.

\footnotetext{
${ }^{9}$ Technically, in the first case of Proposition 4, there are infinitely many symmetric equilibria that involve location choices that do not cause competition. However, all these equilibria are payoff equivalent.
} 


\section{$7 \quad$ Summary and conclusions}

We have considered the addition of two realities, capacity costs and impatient consumers, in a traditional spatial competition setting. We characterized the symmetric subgame perfect equilibrium when two firms pre-commit to a capacity level and then select a location. We showed that, unless capacity costs are very low, in equilibrium firms select limited capacities and then differentiate themselves by selecting locations (either in a physical or in a product-positioning context) as far apart as is practical. Indeed, capacity can be used instead of price to achieve differentiation. By expanding the spatial model to include the important feature of capacity, we generated a number of insights.

First, capacity decisions should not be made ignoring competition, especially in the presence of congestion delays and time-sensitive customers. Traditional models of capacity choice in the Operations Management literature do not address the strategic issue of competition. However, if in the presence of competition, a manager were to make a capacity decision as if she were a monopolist, she would over-invest in capacity. Recently, for example, the Polish coal industry had to downsize its capacity and undergo a major restructuring (including an evaluation of all existing mine locations) to transition to a competitive environment (Suwala and Labys, 2002). On the other hand, competition can lead to higher than expected investments in capacity when its strategic value is considered. In the constrained competition case of Proposition 4, the equilibrium outcome is for both firms to serve half the customers. The firms invest in capacity that would, without competition, allow them to serve more than half the customers; it would be more profitable for both the firms to select capacities that serve exactly half the interval. However, the forces of competition result in greater investment in capacity. If the firm were to unilaterally move to a lower capacity level, their volume of customers would decline by more than the capacity cost savings. This is consistent with the often observed practice of competing firms retaining some unutilized capacity as a strategic threat to their competition.

Second, while it is not surprising that firms with limited capacity decide not to compete directly, what is surprising is that the decision to limit one's capacity can be rationalized by non-cooperative play. Local monopolies without clear natural monopoly characteristics are often considered evidence of collusive behavior. Firms might find it profitable to not compete in each other's local market, 
but, without collusive coordination, they have an incentive to invade each other's market. In our case, however, local monopoly can be supported as the outcome of competitive play. We have demonstrated that for a large selection of input parameters, the equilibrium outcome (local monopoly and constrained local monopoly) is for the two firms to not compete directly for the same (location) consumers.

\section{A Proofs}

Proof of Proposition 1: Suppose the proposed solution is not an equilibrium. Then there must exist a strictly more profitable deviation for one of the firms. Without loss of generality assume firm 1 can profit by the choice of a different location $x_{1}^{\prime}$. Since capacity is fixed from the previous stage, the only way profit could have increased for firm 1 is if they served a greater area of customers, or $\lambda_{1}^{\prime}>\lambda_{1}^{*}$. Consider two cases:

i. Assume firm 1 moves to the left at location $x_{1}^{\prime}<x_{1}^{*}$. Consider two cases:

(a) $\widetilde{S}_{1}^{M}\left(\mu_{1}\right)+\widetilde{S}_{2}\left(\mu_{2}\right)<\frac{1}{2}$. In this case firms are not competing for customers at the proposed equilibrium. Consider the consumer at point $y>x_{1}^{*}$ who was originally indifferent between purchasing or not $\left(U_{y}\left(1 \mid\left(x_{1}^{*}, \mu_{1}\right)\left(x_{2}^{*}, \mu_{2}\right)\right)=0\right)$. Firm 1 is now further from this consumer, and by assumption, serving more customers thus increasing expected waiting time. Therefore, it must be that $U_{y}\left(1 \mid\left(x_{1}^{\prime}, \mu_{1}\right)\left(x_{2}^{*}, \mu_{2}\right)\right)<0$. This is also true for all customers to the right of $y$ or $y^{\prime}>y$. Thus, $\lambda_{1}^{\prime}$ could not have increased.

(b) $\widetilde{S}_{1}^{M}\left(\mu_{1}\right)+\widetilde{S}_{2}^{M}\left(\mu_{2}\right) \geq \frac{1}{2}$. In this case firms are competing for customers at the proposed equilibrium. In order to increase the area served, firm 1 must have taken some customers from firm 2. Consider the consumer at point $y$ who was originally indifferent between firms 1 and 2 . In other words, $U_{y}\left(1 \mid\left(x_{1}^{*}, \mu_{1}\right)\left(x_{2}^{*}, \mu_{2}\right)\right)=U_{y}\left(2 \mid\left(x_{1}^{*}, \mu_{1}\right)\left(x_{2}^{*}, \mu_{2}\right)\right)$. By assumption, $\lambda_{1}^{\prime}>\lambda_{1}^{*}$ and $x_{1}^{\prime}<x_{1}^{*}$, so $U_{y}\left(1 \mid\left(x_{1}^{\prime}, \mu_{1}\right)\left(x_{2}^{*}, \mu_{2}\right)\right)<U_{y}\left(1 \mid\left(x_{1}^{*}, \mu_{1}\right)\left(x_{2}^{*}, \mu_{2}\right)\right)$. Also, $\lambda_{1}^{\prime}>\lambda_{1}^{*}$ must imply that $\lambda_{2}^{\prime}<\lambda_{2}^{*}$ (since the firms served the whole area of customers, or $\left.\lambda_{1}+\lambda_{2}=\ell\right)$. Thus, $U_{y}\left(2 \mid\left(x_{1}^{\prime}, \mu_{1}\right)\left(x_{2}^{*}, \mu_{2}\right)\right)>U_{y}\left(2 \mid\left(x_{1}^{*}, \mu_{1}\right)\left(x_{2}^{*}, \mu_{2}\right)\right)$ which implies $U_{y}\left(2 \mid\left(x_{1}^{\prime}, \mu_{1}\right)\left(x_{2}^{*}, \mu_{2}\right)\right)>U_{y}\left(1 \mid\left(x_{1}^{\prime}, \mu_{1}\right)\left(x_{2}^{*}, \mu_{2}\right)\right)$ or the consumer at point $y$ now prefers to purchase from firm 2. Obviously, this holds for all $y^{\prime}>y$ which contradicts 
the assumption that $\lambda_{1}^{\prime}>\lambda_{1}^{*}$.

ii. Assume firm 1 moves to the right at location $x_{1}^{\prime}>x_{1}^{*}$. Consider three cases:

(a) $\widetilde{S}_{1}^{M}\left(\mu_{1}\right)+\widetilde{S}_{2}^{M}\left(\mu_{2}\right)<\frac{1}{2}$ and $x_{1}^{\prime}<\left(1-2 \widetilde{S}_{2}\left(\mu_{2}\right)-\widetilde{S}_{1}^{M}\left(\mu_{1}\right)\right)$. This is the case were the firms do not overlap at the proposed equilibrium and firm 1 does not move close enough to firm 2 to create an overlap. Trivially, the area served by firm 1 does not change (it simply shifts over by $x_{1}^{\prime}-x_{1}^{*}$ ). This is a contradiction with assumption that the move was strictly more profitable.

(b) $\widetilde{S}_{1}^{M}\left(\mu_{1}\right)+\widetilde{S}_{2}^{M}\left(\mu_{2}\right)<\frac{1}{2}$ and $x_{1}^{\prime}>\left(1-2 \widetilde{S}_{2}\left(\mu_{2}\right)-\widetilde{S}_{1}^{M}\left(\mu_{1}\right)\right)$. In this case firm 1's movement generated an overlap with firm 2 . Note that all consumers between 0 and $x_{1}^{\prime}-x_{1}^{*}$ must now receive negative utility (and therefore do not purchase) from firm 1 . In order for $\lambda_{1}^{\prime}$ to have increased it must therefore be that firm 1 added at least $\left(x_{1}^{\prime}-x_{1}^{*}\right) \ell$ consumers to the right. Let the consumer at point $y$ be the consumer who originally received 0 utility from 1 . If $\lambda_{1}^{\prime}=\lambda_{1}^{*}$, note that the following inequalities would hold:

$$
\begin{gathered}
U_{y}\left(1 \mid\left(x_{1}^{*}, \mu_{1}\right)\left(x_{2}^{*}, \mu_{2}\right)\right)=0=U_{y+\left(x_{1}^{\prime}-x_{1}^{*}\right)}\left(1 \mid\left(x_{1}^{\prime}, \mu_{1}\right)\left(x_{2}^{*}, \mu_{2}\right)\right), \text { and } \\
U_{y}\left(2 \mid\left(x_{1}^{*}, \mu_{1}\right)\left(x_{2}^{*}, \mu_{2}\right)\right)=U_{y}\left(2 \mid\left(x_{1}^{\prime}, \mu_{1}\right)\left(x_{2}^{*}, \mu_{2}\right)\right) \\
\quad<U_{y+\left(x_{1}^{\prime}-x_{1}^{*}\right)}\left(2 \mid\left(x_{1}^{*}, \mu_{1}\right)\left(x_{2}^{*}, \mu_{2}\right)\right)=U_{y+\left(x_{1}^{\prime}-x_{1}^{*}\right)}\left(2 \mid\left(x_{1}^{\prime}, \mu_{1}\right)\left(x_{2}^{*}, \mu_{2}\right)\right) .
\end{gathered}
$$

Under the assumption that $\lambda_{1}^{\prime}>\lambda_{1}^{*}$ it must be that:

$$
\begin{aligned}
& U_{y}\left(1 \mid\left(x_{1}^{*}, \mu_{1}\right)\left(x_{2}^{*}, \mu_{2}\right)\right)=0>U_{y+\left(x_{1}^{\prime}-x_{1}^{*}\right)}\left(1 \mid\left(x_{1}^{\prime}, \mu_{1}\right)\left(x_{2}^{*}, \mu_{2}\right)\right), \text { and } \\
& U_{y}\left(2 \mid\left(x_{1}^{*}, \mu_{1}\right)\left(x_{2}^{*}, \mu_{2}\right)\right)<U_{y}\left(2 \mid\left(x_{1}^{*}, \mu_{1}\right)\left(x_{2}^{*}, \mu_{2}\right)\right) \\
& \quad<U_{y+\left(x_{1}^{\prime}-x_{1}^{*}\right)}\left(2 \mid\left(x_{1}^{*}, \mu_{1}\right)\left(x_{2}^{*}, \mu_{2}\right)\right)<U_{y+\left(x_{1}^{\prime}-x_{1}^{*}\right)}\left(2 \mid\left(x_{1}^{\prime}, \mu_{1}\right)\left(x_{2}^{*}, \mu_{2}\right)\right)
\end{aligned}
$$

which obviously implies that

$$
U_{y+\left(x_{1}^{\prime}-x_{1}^{*}\right)}\left(1 \mid\left(x_{1}^{\prime}, \mu_{1}\right)\left(x_{2}^{*}, \mu_{2}\right)\right)<U_{y+\left(x_{1}^{\prime}-x_{1}^{*}\right)}\left(2 \mid\left(x_{1}^{\prime}, \mu_{1}\right)\left(x_{2}^{*}, \mu_{2}\right)\right) .
$$

This holds for all $y^{\prime}>y+\left(x_{1}^{\prime}-x_{1}^{*}\right)$ implying that $\lambda_{1}^{\prime}$ could not have increased.

(c) $\widetilde{S}_{1}^{M}\left(\mu_{1}\right)+\widetilde{S}_{2}^{M}\left(\mu_{2}\right) \geq \frac{1}{2}$. In this case firm 1's movement generated greater overlap with firm 2. Note that all consumers between 0 and $x_{1}^{\prime}-x_{1}^{*}$ must now receive negative utility (and therefore do not purchase) from firm 1. In order for $\lambda_{1}^{\prime}$ to have increased it must therefore be that firm 1 added at least $\left(x_{1}^{\prime}-x_{1}^{*}\right) \ell$ consumers to the right. Let the 
consumer at point $y$ be the consumer who was originally indifferent between firms 1 and 2. If $\lambda_{1}^{\prime}=\lambda_{1}^{*}$, note that the following inequalities would hold:

$$
\begin{gathered}
U_{y}\left(1 \mid\left(x_{1}^{*}, \mu_{1}\right)\left(x_{2}^{*}, \mu_{2}\right)\right)=U_{y+\left(x_{1}^{\prime}-x_{1}^{*}\right)}\left(1 \mid\left(x_{1}^{\prime}, \mu_{1}\right)\left(x_{2}^{*}, \mu_{2}\right)\right), \text { and } \\
U_{y}\left(2 \mid\left(x_{1}^{*}, \mu_{1}\right)\left(x_{2}^{*}, \mu_{2}\right)\right)=U_{y}\left(2 \mid\left(x_{1}^{\prime}, \mu_{1}\right)\left(x_{2}^{*}, \mu_{2}\right)\right) \\
<U_{y+\left(x_{1}^{\prime}-x_{1}^{*}\right)}\left(2 \mid\left(x_{1}^{*}, \mu_{1}\right)\left(x_{2}^{*}, \mu_{2}\right)\right)<U_{y+\left(x_{1}^{\prime}-x_{1}^{*}\right)}\left(2 \mid\left(x_{1}^{\prime}, \mu_{1}\right)\left(x_{2}^{*}, \mu_{2}\right)\right) .
\end{gathered}
$$

Under the assumption that $\lambda_{1}^{\prime}>\lambda_{1}^{*}$ it must be that:

$$
\begin{gathered}
U_{y}\left(1 \mid\left(x_{1}^{*}, \mu_{1}\right)\left(x_{2}^{*}, \mu_{2}\right)\right)>U_{y+\left(x_{1}^{\prime}-x_{1}^{*}\right)}\left(1 \mid\left(x_{1}^{\prime}, \mu_{1}\right)\left(x_{2}^{*}, \mu_{2}\right)\right), \text { and } \\
U_{y}\left(2 \mid\left(x_{1}^{*}, \mu_{1}\right)\left(x_{2}^{*}, \mu_{2}\right)\right)<U_{y}\left(2 \mid\left(x_{1}^{\prime}, \mu_{1}\right)\left(x_{2}^{*}, \mu_{2}\right)\right) \\
<U_{y+\left(x_{1}^{\prime}-x_{1}^{*}\right)}\left(2 \mid\left(x_{1}^{*}, \mu_{1}\right)\left(x_{2}^{*}, \mu_{2}\right)\right)<U_{y+\left(x_{1}^{\prime}-x_{1}^{*}\right)}\left(2 \mid\left(x_{1}^{\prime}, \mu_{1}\right)\left(x_{2}^{*}, \mu_{2}\right)\right)
\end{gathered}
$$

which obviously implies that

$$
U_{y+\left(x_{1}^{\prime}-x_{1}^{*}\right)}\left(1 \mid\left(x_{1}^{\prime}, \mu_{1}\right)\left(x_{2}^{*}, \mu_{2}\right)\right)<U_{y+\left(x_{1}^{\prime}-x_{1}^{*}\right)}\left(2 \mid\left(x_{1}^{\prime}, \mu_{1}\right)\left(x_{2}^{*}, \mu_{2}\right)\right) .
$$

This holds for all $y^{\prime}>y+\left(x_{1}^{\prime}-x_{1}^{*}\right)$ implying that $\lambda_{1}^{\prime}$ could not have increased.

Proof of Proposition 2: We will show that the Hessian of the restricted Lagrangian function of the constrained duopoly model (i.e., the Lagrangian function considering only the binding inequality constraints), is negative definite in $\left(\mu_{1}, S_{1}\right)$, and thus the problem has a global maximum (see Bazaraa, Sheralli and Shetty 1993, page 168). Letting $u_{1} \geq 0$ and $u_{2} \geq 0$ denote the Lagrange multipliers associated with the two surplus constraints (since consumers will never buy at a negative surplus these multipliers will never be negative). Setting $w_{1} \equiv \ell\left(S_{1}-S_{2}+\frac{1}{2}\right)$, and $w_{2} \equiv \ell\left(S_{2}-\right.$ $\left.S_{1}+\frac{1}{2}\right)$, we can express the restricted Lagrangian as $L \equiv p \ell w_{1}-c \mu_{1}+u_{1}\left(K-\frac{\alpha}{\mu_{1}-w_{1}}\right)+u_{2}(K-$ $\left.\frac{\alpha}{\mu_{2}-w_{2}}\right)$. Therefore, $\frac{\partial^{2}(L)}{\partial^{2} \mu_{1}}=\sum_{i=1}^{2} \frac{-2 \alpha u_{i}}{\left(\mu_{i}-w_{i}\right)^{3}}<0, \frac{\partial^{2}(L)}{\partial^{2} S_{1}}=\sum_{i=1}^{2} \frac{-2 \alpha \ell^{2} u_{i}}{\left(\mu_{i}-w_{i}\right)^{3}}<0$, and $\frac{\partial^{2}(L)}{\partial \mu_{1} \partial S_{1}}=\frac{2 \alpha \ell u_{1}}{\left(\mu_{1}-w_{1}\right)^{3}}>0$. The determinant of the Hessian matrix is thus equal to $4 \alpha^{2} \ell^{2}\left\{\left(\sum_{i=1}^{2} \frac{u_{i}}{\left(\mu_{i}-w_{i}\right)^{3}}\right)^{2}-\left(\frac{u_{1}}{\left(\mu_{1}-w_{1}\right)^{3}}\right)^{2}\right\}=$ $4 \alpha^{2} \ell^{2}\left\{\left(\frac{u_{2}}{\left(\mu_{2}-w_{2}\right)^{3}}\right)^{2}+2 \frac{u_{1} u_{2}}{\left(\mu_{1}-w_{1}\right)^{3}\left(\mu_{2}-w_{2}\right)^{3}}\right\}$, which is strictly positive, implying that the Lagrangian function $L$ is negative definite.

Proof of Proposition 3: By solving the surplus constraint in expression (7) for $S_{2}$, we can express $S_{2}$ as a function of $\mu_{2}$ and $S_{1}: \widetilde{S}_{2}\left(\mu_{2}, S_{1}\right) \equiv \frac{1}{2 \ell}\left(\widetilde{w}\left(\mu_{2}, S_{1}\right)+\frac{2 \ell K}{\alpha G}-\sqrt{\left(\widetilde{w}\left(\mu_{2}, S_{1}\right)\right)^{2}+4 \ell / G}\right)$, where $\widetilde{w}\left(\mu_{2}, S_{1}\right) \equiv \mu_{2}-\ell\left(\frac{K}{\alpha G}-S_{1}+\frac{1}{2}\right)$. Similarly, Solving the surplus constraint in expression (6) for $\mu_{1}$ yields $\widetilde{\mu}_{1}\left(\mu_{2}, S_{1}\right) \equiv \ell\left(S_{1}-\widetilde{S}_{2}\left(\mu_{2}, S_{1}\right)+\frac{1}{2}\right)+\frac{\alpha}{K-\alpha G S_{1}}$. Note that $\widetilde{S}_{2}\left(\mu_{2}, S_{1}\right)$ and $\widetilde{\mu}_{1}\left(\mu_{2}, S_{1}\right)$ are 
distinct from $\widetilde{S}_{2}^{C}\left(\mu_{1}\right)$ and $\widetilde{\mu}_{1}^{C}\left(\mu_{2}\right)$ previously defined. Therefore, for any feasible, but fixed, value of $\mu_{2}$, (i.e., for any $\left.\mu_{2}>2 \ell S_{2}\right)$, we can substitute $\widetilde{S}_{2}\left(\mu_{2}, S_{1}\right)$ and $\widetilde{\mu}_{1}\left(\mu_{2}, S_{1}\right)$ in the profit function of firm 1 and obtain a single-variable maximization problem with respect to $S_{1}$

$$
\max _{S_{1}>0}\left\{(p-c) \ell\left(S_{1}-\widetilde{S}_{2}\left(\mu_{2}, S_{1}\right)+\frac{1}{2}\right)-c \frac{\alpha}{K-\alpha G S_{1}}\right\}
$$

By setting the derivative, with respect to $S_{1}$, of the profit expression (9) equal to zero and solving for $S_{1}$ we conclude that the optimal solution satisfies the relationship

$$
\widetilde{S}_{1}^{C}\left(\mu_{2}\right)=\frac{K}{\alpha G}-\sqrt{c /\left(\ell G(p-c)\left(1-\frac{\partial \widetilde{S}_{2}\left(\mu_{2}, S_{1}\right)}{\partial S_{1}}\right)\right)} .
$$

Let us now compare this last expression with expression (3) which provides us with $S^{M}$ for the monopolist. We see that if $\left(1-\frac{\partial \widetilde{S}_{2}\left(\mu_{2}, S_{1}\right)}{\partial S_{1}}\right)<2$, then we can conclude that $\widetilde{S}_{1}^{C}\left(\mu_{2}\right)<S^{M}$. Differentiating $\widetilde{S}_{2}\left(\mu_{2}, S_{1}\right)$ we obtain $\frac{\partial \widetilde{S}_{2}\left(\mu_{2}, S_{1}\right)}{\partial S_{1}}=\frac{1}{2}\left(1-\widetilde{w}\left(\mu_{2}, S_{1}\right) / \sqrt{\left(\widetilde{w}\left(\mu_{2}, S_{1}\right)\right)^{2}+4 \ell / G}\right)$, which always lies between zero and one (for any $\widetilde{w}\left(\mu_{2}, S_{1}\right)$ ). Therefore, we proved that $\widetilde{S}_{1}^{C}\left(\mu_{2}\right)<S^{M}$. To compare the capacities, first observe that from expression (6) we have $\widetilde{\mu}_{1}^{C}\left(\mu_{2}\right)=\ell\left[\widetilde{S}_{1}^{C}\left(\mu_{2}\right)+\widetilde{S}_{1}^{C}\left(\mu_{2}\right)-\right.$ $\left.\widetilde{z}^{C}\left(\mu_{2}\right)\right]+\frac{\alpha}{K-\alpha G \widetilde{S}_{1}^{C}\left(\mu_{2}\right)}$, where $\widetilde{z}^{C}\left(\mu_{2}\right) \geq 0$ denotes the optimal area of overlap between the two firms as a function of $\mu_{2}$. Since $\widetilde{S}_{1}^{C}\left(\mu_{2}\right)<S^{M}$, we know that $\frac{\alpha}{K-\alpha G \widetilde{S}_{1}^{C}\left(\mu_{2}\right)}<\frac{\alpha}{K-\alpha G S^{M}}$, and that $\ell\left[\widetilde{S}_{1}^{C}\left(\mu_{2}\right)+\widetilde{S}_{1}^{C}\left(\mu_{2}\right)-\widetilde{z}^{C}\left(\mu_{2}\right)\right] \leq 2 \ell \widetilde{S}_{1}^{C}\left(\mu_{2}\right)<2 \ell S^{M}$. Therefore, $\widetilde{\mu}_{1}^{C}\left(\mu_{2}\right)=\ell\left[\widetilde{S}_{1}^{C}\left(\mu_{2}\right)+\widetilde{S}_{1}^{C}\left(\mu_{2}\right)-\right.$ $\left.\widetilde{z}^{C}\left(\mu_{2}\right)\right]+\frac{\alpha}{K-\alpha G \widetilde{S}_{1}^{C}\left(\mu_{2}\right)}<2 \ell S^{M}+\frac{\alpha}{K-\alpha G S^{M}}=\mu^{M}$.

Lemma 1 A pure strategy equilibrium exists in the constrained competition case.

Proof: Let $\widehat{S}_{1}^{C}\left(\mu_{1}, \mu_{2}\right)$ and $\widehat{S}_{2}^{C}\left(\mu_{1}, \mu_{2}\right)$ denote the furthest away, positive-surplus customer served given capacities $\mu_{1}, \mu_{2}$ if the firms were constrained duopolists. These functions are derived by solving the binding constraints (6) and (7) with respect to $S_{1}$ and $S_{2}$. Then the profit function becomes $\pi_{1}^{C}\left(\mu_{1}, \mu_{2}\right) \equiv p \ell\left(\widehat{S}_{1}^{C}\left(\mu_{1}, \mu_{2}\right)+\widehat{S}_{2}^{C}\left(\mu_{1}, \mu_{2}\right)-\frac{1}{2}\right)-c \mu_{1}$. To guarantee the existence of an equilibrium for the CCM, we require the continuity of the profit function $\pi_{1}^{C}\left(\mu_{1}, \mu_{2}\right)$ in $\left(\mu_{1}, \mu_{2}\right)$, and the quasiconcavity of $\pi_{1}^{C}\left(\mu_{1}, \mu_{2}\right)$ in $\mu_{1}$ (Glicksberg, 1952). Because the surplus constraints (6) and (7) are continuously differentiable functions of $\left(\mu_{1}, \mu_{2}\right)$, we can show that $\widehat{S}_{1}^{C}\left(\mu_{1}, \mu_{2}\right)$ and $\widehat{S}_{2}^{C}\left(\mu_{1}, \mu_{2}\right)$ are differentiable and thus continuous functions of $\left(\mu_{1}, \mu_{2}\right)$. Moreover, we have already 
proven that the CCM has a unique global optimal solution, and thus the profit function $\pi_{1}^{C}\left(\mu_{1}, \mu_{2}\right)$ must be quasiconcave in $\mu_{1}$.

Proof of Proposition 4: Let $Q_{1}=\frac{2 \ell(K-\alpha G / 4)^{2}}{\alpha^{2} G}, Q_{2}=\frac{Q_{3}}{\sqrt{Q_{3}^{2}+4 \ell / G}}$, and $Q_{3}=\left(\frac{\ell}{4}+\frac{\alpha}{K-\alpha G / 4}-\frac{\ell K}{\alpha G}\right)$. The condition in case i) is determined by solving the equality $S^{M}=\frac{1}{4}$ with respect to $c$ where $S^{M}$ is the monopolist optimal solution from equation (3). When $c \geq\left(\frac{Q_{1}}{1+Q_{1}}\right) p=c_{M}$, the optimal (monopoly) profits can be obtained in the competitive case as long as firms do not select locations in the second stage that cause overlap. From Proposition 1, setting $x_{1}^{*}=S^{M}$ and $x_{2}^{*}=1-S^{M}$ will constitute a Nash equilibrium in the second stage that does not result in overlap.

Whenever $c<c_{M}$, the monopoly solution prescribes that $S^{M}>\frac{1}{4}$. Given the strategies in stage 2, the firms would have some overlap, making the monopoly formulation invalid. Therefore, the (CCM) model might apply. In Lemma 1, we show that a pure strategy Nash equilibrium for the CCM will exist. A symmetric equilibrium of the CCM will be a simultaneous solution to the CCM for both firms such that $\mu_{1}^{*}=\mu_{2}^{*}$ where $\mu_{1}^{*}=\widetilde{\mu}_{1}^{C}\left(\mu_{2}^{*}\right)$ and $\mu_{2}^{*}=\widetilde{\mu}_{2}^{C}\left(\mu_{1}^{*}\right)$. Given a $\mu_{1}^{*}$ and the recognition that in any symmetric equilibrium it must be that the firms each serve half the interval of customers, we can also characterize the firms' equilibrium locations using Proposition 1 by setting $U_{0}\left(1 \mid x_{1}^{*}, \mu_{1}^{*}, \frac{1}{2} \ell\right)$ and $U_{1}\left(2 \mid x_{2}^{*}, \mu_{2}^{*}, \frac{1}{2} \ell\right)$ from expression (1) equal to zero.

For the CCM model to hold, it must be that expression (8) is satisfied (non-binding). The extreme case for the CCM model (where expression (8) becomes binding) is where $x_{1}^{*}=\frac{1}{4}$. and $x_{2}^{*}=\frac{3}{4}$. From Proposition 1 , this implies that $\widetilde{S}_{1}^{C}\left(\mu_{2}^{*}\right)=\widetilde{S}_{2}^{C}\left(\mu_{1}^{*}\right)=\frac{1}{4}$. Setting $S_{1}=S_{2}=\frac{1}{4}$ and solving the surplus constraint (7) as an equality yields that $\mu_{2}^{*}=\ell / 2+\frac{\alpha}{K-\alpha G / 4}$. Substituting these values for $S_{1}, S_{2}$, and $\mu_{2}^{*}$ in expression (10) and solving for $c$ yields the break point $\left(\frac{1+Q_{2}}{1+Q_{2}+4 / Q_{1}}\right) p=$ $c_{L}$ for case iii).

Notice that $c_{L}=\left(\frac{1+Q_{2}}{1+Q_{2}+4 / Q_{1}}\right) p<\left(\frac{Q_{1}}{1+Q_{1}}\right) p=c_{M}$. Therefore, there exist some parameters where neither the monopoly nor the CCM model apply. However, it is easy to see what the equilibrium must entail in this case. If the symmetric capacity choices were such that the firms served less than half the interval, then we would be in the monopoly case. This is a contradiction with the assumption that $c<\left(\frac{Q_{1}}{1+Q_{1}}\right) p$, so firms cannot be serving less than half the interval. If the symmetric equilibrium was such that both firms served greater than half the interval, again we have contradiction with the necessary conditions to be in the CCM model (i.e., $c<c_{L}$ ). Firms 
must, therefore, be serving exactly half the interval of customers. This result is consistent with Proposition 3 that states that there exists a gap between the monopoly and constrained competition optimal solutions.

Proof of Proposition 5: The proof proceeds in a similar fashion to the derivation of the bounds for the second case (constrained local monopoly) of Proposition 4 except that each firm now faces a differently sized opponent. In order for $x_{1}^{*}=S_{1}$ and $x_{2}^{*}=S_{2}$ to be a Nash equilibrium it must be that each firm serves an area smaller than they would if they were a monopolist. If the prescribed areas were larger, the firm would unilaterally decide to be smaller and serve $S^{M}$ where $S^{M}$ is given in expression (3). In other words, we need that $S_{1} \leq S^{M}$ and $S_{2} \leq S^{M}$. Since $S_{1}>S_{2}$, it is sufficient to find where $S_{1} \leq \frac{K}{\alpha G}-\sqrt{c / 2 \ell G(p-c)}$. Solving for $c$ yields $c \leq\left(\frac{\left(\frac{K}{\alpha G}-S_{1}\right)^{2} 2 \ell}{1+\left(\frac{K}{\alpha G}-S_{1}\right)^{2} 2 \ell}\right) p$.

It must also be the case that neither firm wants to unilaterally increase its size (causing overlap with the other firm) given the size and location of the other firm. Therefore, we need that the CCM model does not hold for either firm. Given that $x_{1}^{*}=S_{1}$ and $x_{2}^{*}=1-S_{2}$, for the CCM to not hold it must be that $\widetilde{S}_{1}^{C}\left(\mu_{2}^{*}\right) \leq S_{1}$ and $\widetilde{S}_{2}^{C}\left(\mu_{1}^{*}\right) \leq S_{2}$. Since $S_{1}>S_{2}$ and $\mu_{1}^{*}>\mu_{2}^{*}$, it is straightforward that if $\widetilde{S}_{2}^{C}\left(\mu_{1}^{*}\right) \leq S_{2}$ then $\widetilde{S}_{1}^{C}\left(\mu_{2}^{*}\right) \leq S_{1}$. Solving the binding surplus constraints (6) yields $\mu_{1}^{*}=2 \ell S_{1}+\frac{\alpha}{K-\alpha G S_{1}}$. Substituting $\mu_{1}^{*}$ into the equivalent of expression (10) for firm 2 yields the following optimal capacity expression for the CCM model for firm 2: $\widetilde{S}_{2}^{C}=\frac{K}{\alpha G}-\sqrt{\frac{c}{2 \ell G(p-c)(1-T)}}$. (Notice that $T=\frac{1}{2}\left(1-\frac{w}{\sqrt{w^{2}+\frac{4 \ell}{G}}}\right)$ is simply the equivalent of the partial derivative appearing in expression (10) for firm 2, and $w$ is similarly defined as in the proof of Proposition 3. Since we need the CCM to not hold it must be that $S_{2} \geq \widetilde{S}_{2}^{C}$ or $S_{2} \geq \frac{K}{\alpha G}-\sqrt{\frac{c}{2 \ell G(p-c)(1-T)}}$. Solving for $c$ yields $c \geq\left(\frac{\left(\frac{K}{\alpha G}-S_{2}\right)^{2} 2 \ell(1-T)}{1+\left(\frac{K}{\alpha G}-S_{2}\right)^{2} 2 \ell(1-T)}\right) p$.

For any marginal cost between these two bounds, at the prescribed capacity and location, neither firm will want to get smaller and act like a local monopolist or get larger and move into a situation of constrained competition (the CCM).

Proof of Proposition 6: Given the assumption of symmetric capacity choices, each firm would serve exactly half the customers $\left(\lambda_{1}^{*}=\lambda_{2}^{*}=\frac{1}{2} \ell\right)$ if they were to co-locate at $x_{1}^{*}=x_{2}^{*}=\frac{1}{2}$. Suppose the proposed location choices are not an equilibrium. Then it must be that one of the firms found it profitable (served more customers) by moving to a location other than the mid-point. Without loss of generality, assume that firm 1 served more customers $\left(\lambda_{1}^{\prime}>\frac{1}{2} \ell\right)$ by selecting a 
location $x_{1}^{\prime}<\frac{1}{2}$. Let $y$ be the location of a consumer who is indifferent between firm 1 and 2 , or $U_{y}\left(1 \mid\left(x_{1}^{\prime}, \mu_{1}\right)\left(x_{2}^{*}, \mu_{2}\right)\right)=U_{y}\left(2 \mid\left(x_{1}^{\prime}, \mu_{1}\right)\left(x_{2}^{*}, \mu_{2}\right)\right)$. In order for $\lambda_{1}^{\prime}>\frac{1}{2} \ell$ to hold, it must be that $y>\frac{1}{2}$. However, for a consumer at this location, firm 2 (located at $x_{2}^{*}=\frac{1}{2}$ ) offers greater utility since firm 1 is serving more customers (increasing expected waiting time) and firm 2 is closer $\left(y-x_{2}^{*}=y-\frac{1}{2}<y-x_{1}^{\prime}\right)$, or $U_{y}\left(1 \mid\left(x_{1}^{\prime}, \mu_{1}\right)\left(x_{2}^{*}, \mu_{2}\right)\right)<U_{y}\left(2 \mid\left(x_{1}^{\prime}, \mu_{1}\right)\left(x_{2}^{*}, \mu_{2}\right)\right)$ and we have a contradiction.

Proof of Proposition \%: From Proposition 6 we know that if there is a symmetric equilibrium with both firms serving the whole interval, it will involve firms co-locating at $x_{1}^{*}=x_{2}^{*}=\frac{1}{2}$. Then the customers will randomly select a firm (since they are indifferent) such that the expected waiting time are equivalent (i.e., $W\left(\mu_{1}, \lambda_{1}\right)=W\left(\mu_{2}, \lambda_{2}\right)$, or $\left.\frac{1}{\mu_{1}-\lambda_{1}}=\frac{1}{\mu_{2}-\lambda_{2}}\right)$. Since, taken together, both firms must be serving all customers (which is necessary for co-location), we know that $\lambda_{1}+\lambda_{2}=\ell$. Substituting $\lambda_{2}=\ell-\lambda_{1}$ into the waiting time equality we can solve for $\lambda_{1}$ in terms of $\mu_{1}$ and $\mu_{2}$ as $\lambda_{1}=\frac{\mu_{1}-\mu_{2}+\ell}{2}$. This last expression tells us how, contingent upon being in the co-location case, firm 1's customers will respond to changes in both its own capacity and firm 2's capacity. Firm 1's profit function is then given by:

$$
\pi_{1}\left(\mu_{1}, \mu_{2}\right)=p\left(\frac{\mu_{1}-\mu_{2}+\ell}{2}\right)-c \mu_{1}
$$

In equilibrium, given a choice of capacity by firm 2 , firm 1 will maximize its profits by optimally choosing its own capacity. Taking the derivative of equation (11) above with respect to $\mu_{1}$ yields $\frac{\partial \pi_{1}}{\partial \mu_{1}}=\frac{p}{2}-c$. If $p<2 c$, the derivative is always negative and firm 1 would want to unilaterally lower its capacity. This implies that the only possible equilibrium will have the lowest possible feasible capacity (assuming both firms have co-located). This capacity is found by setting the extreme customers expected utility at zero given that each firm is serving half of the customers, or $\mu_{1}=\frac{1}{\frac{K}{\alpha}-.5 G}+.5 \ell$

If $p>2 c$, the derivative is positive for all values of $\mu_{1}$ and firm 1 would always want to unilaterally increase its capacity. Since there is no upper bound on capacity, this implies that there will not exist an equilibrium in this case.

Proof of Proposition 8: Suppose that there did exist a Nash equilibrium to the simultaneous move 
game such that $\widetilde{S}_{1}^{M}\left(\mu_{1}^{*}\right)<\frac{1}{2}$ and $\widetilde{S}_{2}^{M}\left(\mu_{2}^{*}\right)<\frac{1}{2}$ and at least one of the firms provided positive expected surplus to at least one of the extreme customers. Following Proposition 1, we know that the firm would benefit by selecting a different location where the customer received zero expected surplus. 


\section{B Figures and Tables}

\section{B.1 Figures}

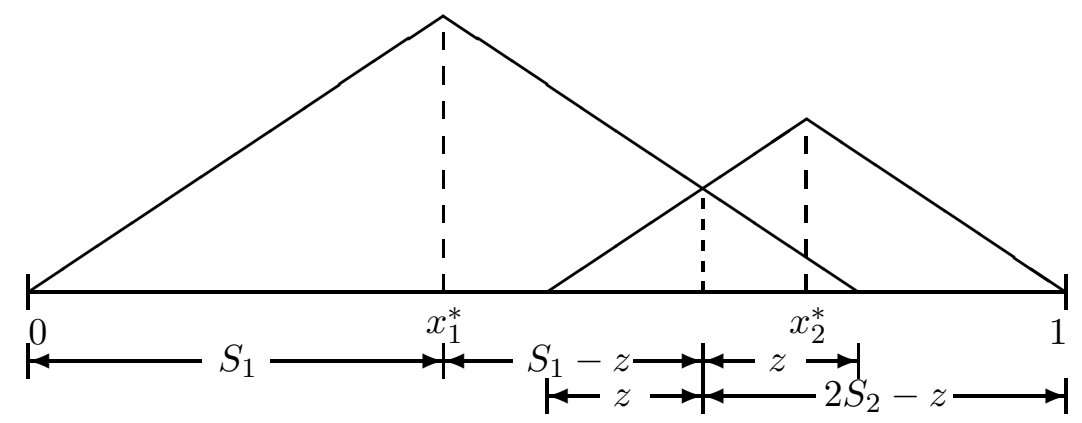

Figure 1: Constrained competition area served calculations. 


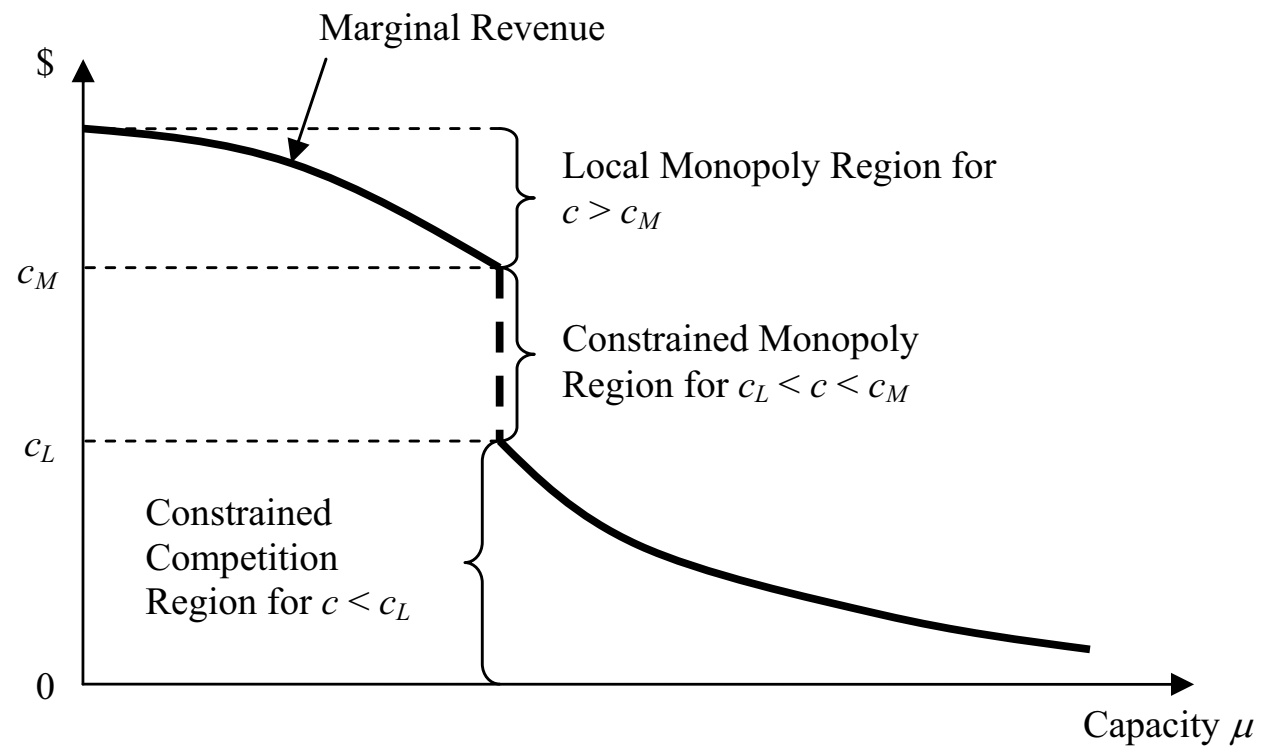

Figure 2: Marginal revenue as a function of capacity choice for a duopolist given a fixed capacity choice by the other firm. The value of the marginal cost of capacity $c$ relative to the marginal revenue determines the resulting type of equilibrium. 
Type 1: Local Monopoly
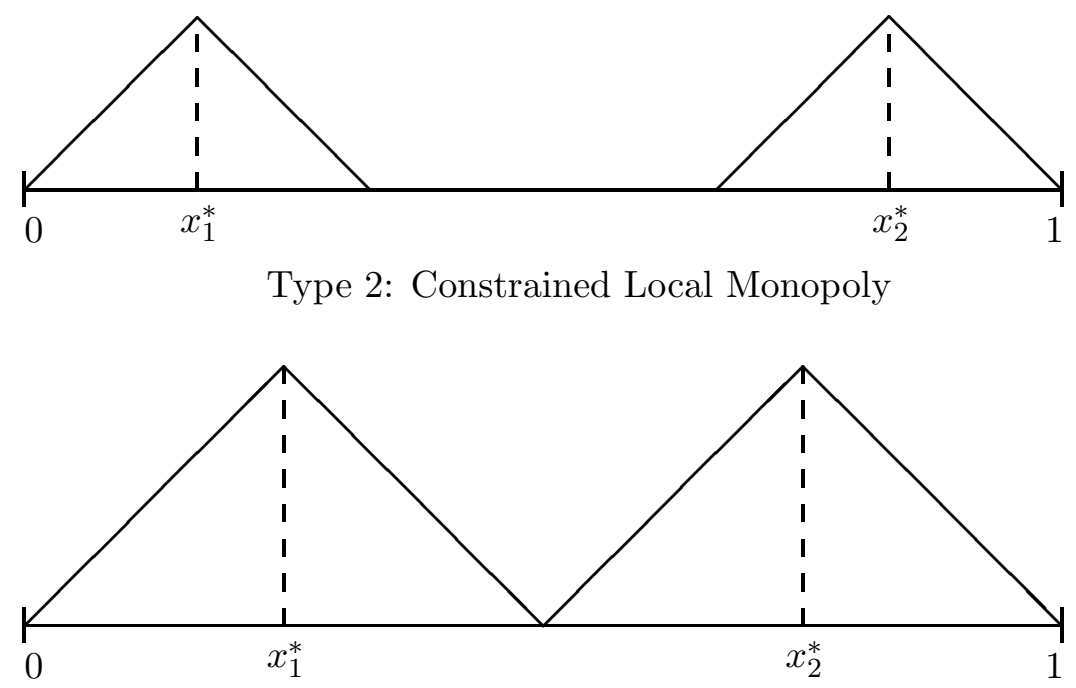

Type 3: Constrained Competition

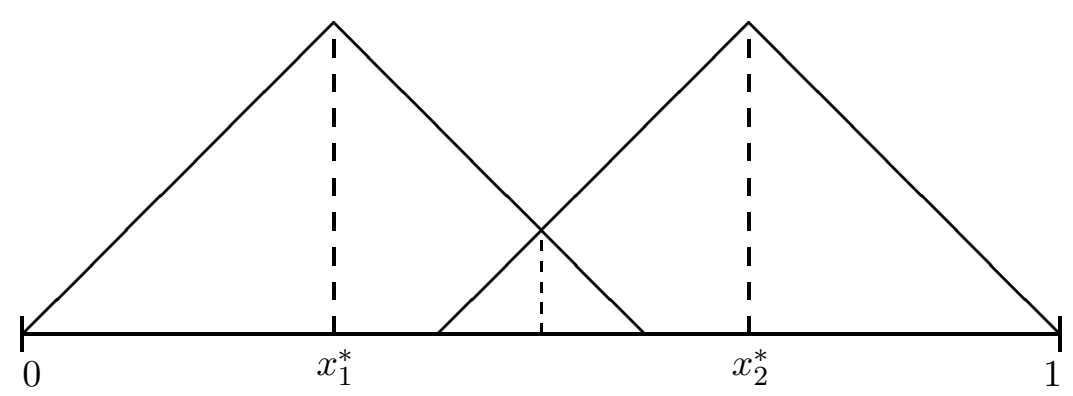

Figure 3: The three types of symmetric subgame perfect equilibria. 

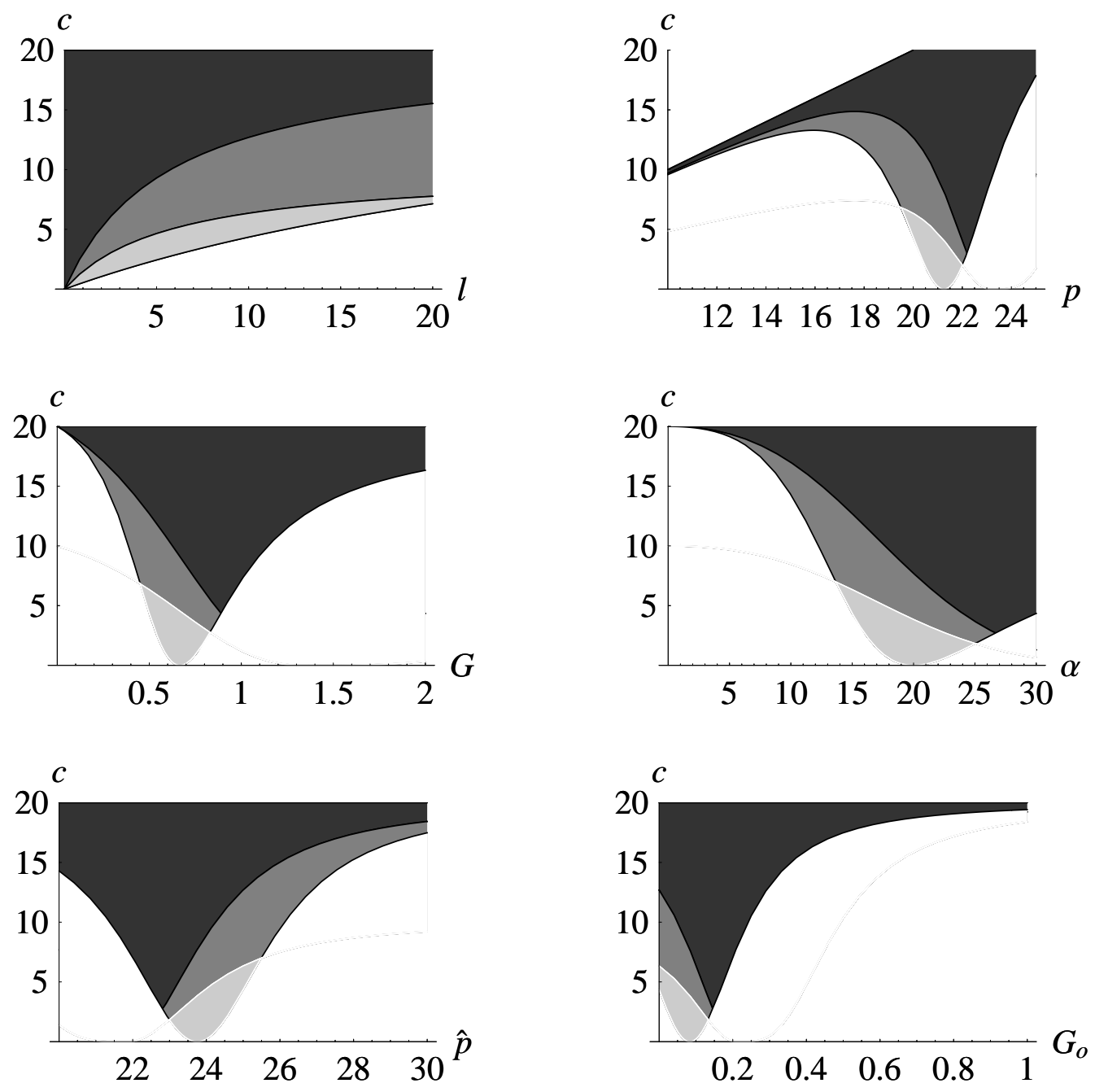

Figure 4: Equilibrium regions as a function of capacity cost $(c)$ and one parameter variable. The base case is $\widehat{p}=25, p=20, \ell=10, G_{O}=0, G=.5, \alpha=15$. Shades correspond to local monopoly (darkest), constrained local monopoly (medium), and constrained competition (lightest) regions. 


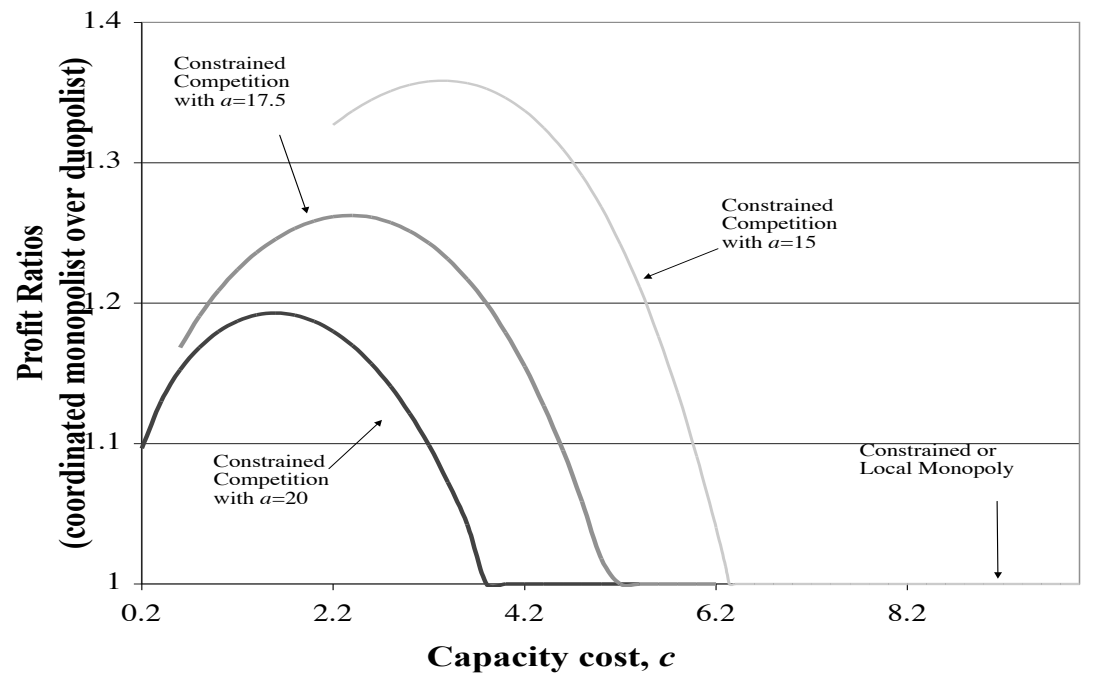

(a) The profit ratio as marginal cost of capacity varies for three different $\alpha$ values.

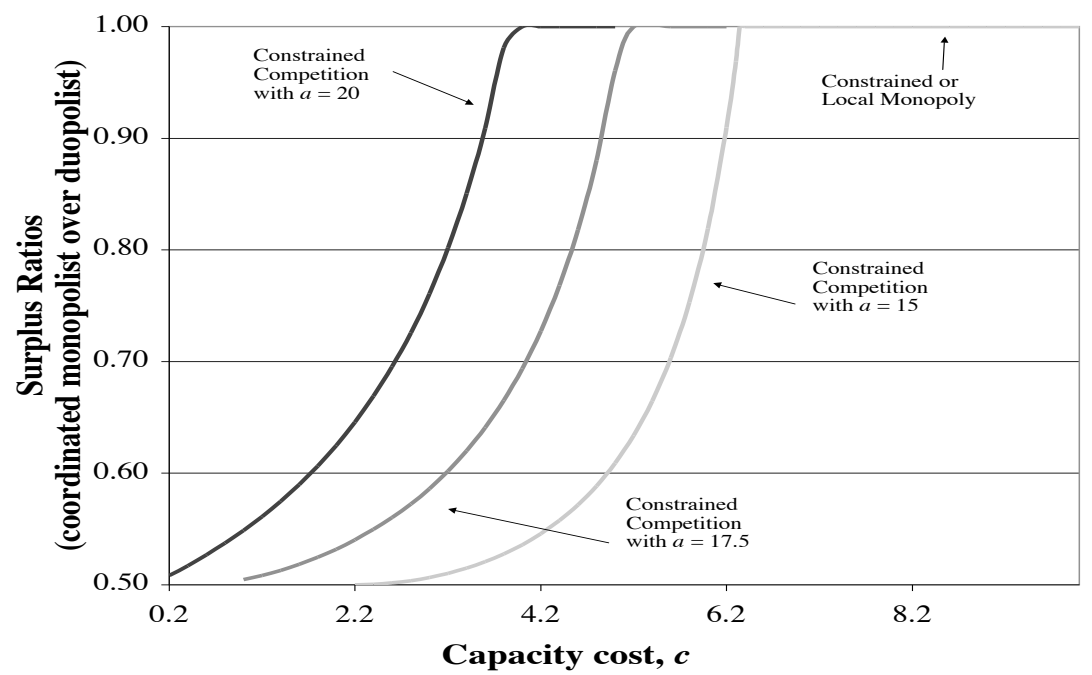

(b) The consumer surplus ratio as marginal cost of capacity varies for three different $\alpha$ values.

Figure 5: Comparison of the duopoly equilibrium with coordinated monopoly. 


\section{B.2 Tables}

\begin{tabular}{rccccc}
\hline \hline & \multicolumn{5}{c}{ Optimal/Equilibrium Values } \\
& $\mu$ & $S$ & $z$ & $\pi$ & $R$ \\
\hline Coordinated Monopolist & 9.8 & .25 & N/A & 51 & 0.47 \\
Constrained Duopolist & 11.32 & .35 & .2 & 43.38 & 0.77 \\
\hline \hline
\end{tabular}

Table 1: Optimal/Equilibrium solutions for our base case numerical example. The numbers in each row represent the outcomes for one facility. Therefore, profits and consumer surplus are doubled in ordered to obtain total results.

\begin{tabular}{|c|c|c|c|c|c|c|c|c|c|}
\hline & \multicolumn{4}{|c|}{ Coordinated Monopolist } & \multicolumn{5}{|c|}{ 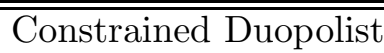 } \\
\hline Parameter & $\mu$ & $S$ & $\pi$ & $R$ & $\mu$ & $S$ & $z$ & $\pi$ & $R$ \\
\hline$c$ & 0 & 0 & - & 0 & - & - & - & - & - \\
\hline$\widehat{p}$ & - & 0 & + & 0 & 0 & + & + & 0 & + \\
\hline$\alpha$ & + & 0 & - & + & 0 & - & - & 0 & - \\
\hline$G$ & + & 0 & - & + & - & - & - & + & - \\
\hline
\end{tabular}

Table 2: Comparative statics results for a coordinated monopolist or a constrained duopolist 


\section{References}

[1] Bazaraa, M.S., H.D. Sherali and C.M. Shetty. 1993. Nonlinear Programming. Theory and Algorithms. 2nd Edition, John Wiley \& Sons, Inc.

[2] Boyaci, T., Saibal R. 2003. Product differentiation and capacity cost interaction in time and price sensitive markets. Manufacturing $\&$ Service Operations Management. 5(1) 18-36.

[3] Blackburn, J.D., T. Elrod, W.B. Lindsley, A.J. Zahorik. 1992. The strategic value of response time and product variety. C.A. Voss, ed. Manufacturing Strategy-Process and Content. Chapman and Hall, London, U.K.

[4] Cachon, G.P. and P.T. Harker. 2002. Competition and outsourcing with scale economies. Management Science. 48(10) 1314-1333.

[5] Chayet, S. and W.J. Hopp. 2002. Sequential entry with capacity, price, and leadtime competition. The University of Chicago working paper, Chicago, IL.

[6] D'Aspermont, C., J.J. Gabszewicz, and J.F. Thisse. 1979. On Hotelling's "Stability in competition". Econometrica 47(5) 1145-1150.

[7] DePalma, A., Y.Y. Ginsburgh, and J.F. Thisse. 1985. The principle of minimal differentiation holds under sufficient heterogeneity. Econometrica 53, 767-781.

[8] Dewan, S. and H. Mendelson. 1990. User delay costs and international pricing for a service facility. Management Science 36 1502-1517.

[9] Dobson, G. and E. Stavrulaki. 2006. Simultaneous Price, Location, and Capacity Decisions on a Line of Time Sensitive Customers. Naval Research Logistics, forthcoming.

[10] Downs, A. 1957. An Economic Theory of Democracy. Harper and Row, New York.

[11] Economides, N. 1984. The Principle of Minimum Differentiation Revisited. European Economic Review 24 345-368.

[12] Eiselt, H.A. 1998. Perception and information in a competitive location model. European Journal of Operational Research 108 94-105.

[13] Eiselt, H.A., G. Laporte and J.F. Thisse. 1993. Competitive location model: A framework and bibliography. Transportation Science 27 44-54.

[14] Fudenberg, D. and J. Tirole. 1993. Game Theory. MIT Press, Cambridge, Massachusetts.

[15] Gilbert, S.M. and Z.K. Weng. 1998. Incentive effects favor non consolidation queues in a service system: The principal-agent perspective. Management Science 44(12) 1662-1669.

[16] Glicksberg, I.L. 1952. A further generalization of the Kakutani fixed point theorem with application to Nash equilibrium points. Proceedings of the National Academy of Sciences 38 $170-174$.

[17] Ha, A.Y. 1998. Incentive-compatible pricing for a service facility with joint production and congestion externalities. Management Science 44 12(1) 1623-1636.

[18] Hotelling, H. 1929. Stability in competition Economic Journal 39 41-57. 
[19] Hum, S-H. and Sim H-H. 1996. Time-based competition: Literature review and implications for modeling. International Journal of Operations and Production Management 16 75-90.

[20] Kalai, E., M.I. Kamien and M. Rubinovitch. 1992. Optimal service speeds in a competitive environment. Management Science 38(8) 1154-1163.

[21] Lancaster, K. 1990. The economics of product variety: A survey. Marketing Science 9(3) 189-206.

[22] Lederer, P.J. and L. Li. 1997. Pricing, production, scheduling, and delivery time competition. Operations Research, 45(3) 407-420.

[23] Lederer, P.J. and A.P. Hurter. 1986. Competition of firms: Discriminatory pricing and location. Econometrica, $\mathbf{5 4}$ 623-640.

[24] Lerner, A.P. and H.W. Singer. 1937. Some notes on duopoly and spatial competition. Journal of Political Economy, 45(2) 145-186.

[25] Li, L. and Y.S. Lee. 1994. Pricing and delivery time performance in a competitive environment. Management Science 40(5) 633-646.

[26] Loch, C.H. 1992. Pricing in markets sensitive to delay. Ph.D. thesis, Stanford University.

[27] Mendelson, H. 1985. Pricing computer services: Queueing effects. Comm. ACM 28(3) 312-321.

[28] Mendelson, H. and S. Whang. 1990. Optimal incentive-compatible priority pricing for the M/M/1 queue. Operations Research 38(5) 870-883.

[29] Milmo, S. 2002. Bulk polymer producers shift business to independent compounders. Chemical Market Reporter 262(12) 6.

[30] Reitman, D. 1991. Endogenous quality differentiation in congested markets. Journal of Industrial Economics 39 621-647.

[31] Rump, C.M. and S. Stidham Jr. 1998. Stability and chaos in input pricing for a service facility with adaptive customer response to congestion. Management Science 44(2) 246-261.

[32] So, K.C. 2002. Price and time competition for service delivery. Manufacturing Service Operations Management 2(4) 392-409.

[33] Stidham, S. Jr. 1992. Pricing and capacity decisions for a service facility: Stability and multiple local optima. Management Science 38(8) 1121-1139.

[34] Stalk, G. and T.M. Hout. 1990. Competing against time: How time-based competition is reshaping global markets. The Free Press, New York.

[35] Suwala, W. and W.C. Labys. 2002. Market transition and regional adjustments in the Polish coal industry. Energy Economics 24 285-303.

[36] Van Mieghem, J.A. 2000. Price and service discrimination in queuing systems: Incentive compatibility of G $c \mu$ scheduling. Management Science 46(9) 1249-1267. 